\title{
Brain structural and functional abnormalities in mood disorders: implications for neurocircuitry models of depression
}

\author{
Wayne C. Drevets · Joseph L. Price • \\ Maura L. Furey
}

Received: 23 January 2008 / Accepted: 20 June 2008/Published online: 13 August 2008

(c) The Author(s) 2008. This article is published with open access at Springerlink.com

\begin{abstract}
The neural networks that putatively modulate aspects of normal emotional behavior have been implicated in the pathophysiology of mood disorders by converging evidence from neuroimaging, neuropathological and lesion analysis studies. These networks involve the medial prefrontal cortex (MPFC) and closely related areas in the medial and caudolateral orbital cortex (medial prefrontal network), amygdala, hippocampus, and ventromedial parts of the basal ganglia, where alterations in grey matter volume and neurophysiological activity are found in cases with recurrent depressive episodes. Such findings hold major implications for models of the neurocircuits that underlie depression. In particular evidence from lesion analysis studies suggests that the MPFC and related limbic and striato-pallido-thalamic structures organize emotional expression. The MPFC is part of a larger "default system" of cortical areas that include the dorsal PFC, mid- and posterior cingulate cortex, anterior temporal cortex, and entorhinal and parahippocampal cortex, which has been implicated in self-referential functions. Dysfunction within and between structures in this circuit may induce disturbances in emotional behavior and other cognitive aspects of depressive syndromes in humans. Further, because the
\end{abstract}

W. C. Drevets $(\bowtie) \cdot$ M. L. Furey

Section on Neuroimaging in Mood and Anxiety Disorders,

National Institute of Mental Health, National Institutes

of Health (NIH/NIMH DIRP), 15K North Dr., Room 210,

Bethesda, MD 20892, USA

e-mail: drevetsw@mail.nih.gov

J. L. Price

Department of Anatomy and Neurobiology,

Washington University School of Medicine,

St Louis, MO 63110, USA
MPFC and related limbic structures provide forebrain modulation over visceral control structures in the hypothalamus and brainstem, their dysfunction can account for the disturbances in autonomic regulation and neuroendocrine responses that are associated with mood disorders. This paper discusses these systems together with the neurochemical systems that impinge on them and form the basis for most pharmacological therapies.

The World Health Organization ranks major depressive disorder (MDD) and bipolar disorder (BD) as the first and fifth leading causes of years lived with disability (WHO 2001), respectively, yet almost nothing is known about their pathogenesis. Because these conditions were not associated with gross brain pathology or with clear animal models for spontaneous, recurrent mood episodes, the availability of tools allowing noninvasive assessment of the human brain proved critical to elucidating their neurobiology. The recent development of neuroimaging technologies that permit in vivo characterization of the anatomical, physiological and neurochemical correlates of mood disorders thus has enabled significant advances toward illuminating the pathophysiology of these conditions. Notably, the results of neuroimaging studies and the post mortem studies that have been guided by neuroimaging results have given rise to neurocircuitry-based models in which both functional and structural brain pathology play roles in the development of mood disorders.

The symptomatology of the clinical syndrome shared by MDD and BD, namely the major depressive episode, implicates brain systems involved in the regulation of mood and emotional expression, reward processing, attention, motivation, stress responses, social cognition and neurovegetative function (e.g., sleep, appetite, energy, libido). 
For example, the diagnostic criteria for major depressive episodes (MDE) require persistence of either depressed mood or loss of interest and pleasure, in association with at least four of the following symptoms: inattention, fatigue, self-depreciating or suicidal thoughts, and disturbances of psychomotor activity, sleep, appetite and weight (APA 1994). Anxiety symptoms also are prominent during MDE, and mood disorders commonly occur comorbidly with anxiety disorders such as panic disorder, social phobia, posttraumatic stress syndrome and obsessive-compulsive disorder (Kessler et al. 2005). These comorbid syndromes generally worsen or improve in tandem with the severity of depressive symptoms. In BD episodes of depression occur alternately with manic or hypomanic episodes, during which the mood becomes euphoric and labile, the capacity for deriving pleasure increases, behaviors aimed at deriving pleasure increase, and energy, psychomotor activity, libido and self esteem become elevated. The symptomatology for mania thus implicates the same functional domains as those that characterize MDE, but in a manner that is phenomenologically antithetical.

In this paper, we consider the neurobiological bases of these clinical features by reviewing the abnormalities of brain structure and function that have been discovered in patients with mood disorders, and integrate these findings with information obtained about the function of putatively homologous brain systems in experimental animals. The data acquired from depressed patients that are presented below emphasize morphological, physiological and chemical data assessed via in vivo neuroimaging and post mortem neuropathological techniques. The neuroanatomical information contained within these studies are discussed by considering the prominent neural connections between implicated brain regions to construct circuit-based models that suggest mechanisms by which dysfunction can precipitate the behavioral signs and symptoms of affective disease. We propose specifically a neural model in which dysfunction within the MPFC and in the circuits that connect the MPFC to other cortical and limbic structures can account for the disturbances of emotional behavior, cognitive performance, neurotransmission, autonomic regulation and neuroendocrine responses that are associated with mood disorders.

\section{Neurobiological correlates of mood disorders}

Despite many psychological and biological theories regarding the pathogenesis of mood disorders the etiologies of primary MDD and BD remain unknown. The spontaneous and perseverative nature of MDE symptoms and their responsiveness to antidepressant drugs suggest abnormal brain processes that underlie and maintain these conditions. Consistent with this expectation a variety of neurophysiological, neuropathological, and neurochemical abnormalities has been discovered in MDD and BD within the neural systems that modulate emotional behavior. None of these abnormalities has shown sufficient sensitivity and specificity to prove useful as a diagnostic test, however.

The variable presence and magnitude of such abnormalities in mood disorders likely reflects the heterogeneity encompassed within the MDD and BD syndromes with respect to pathophysiology and etiology. So long as psychiatric nosology depends on syndrome-based classifications, diagnoses for MDD will continue to encompass patients with a wide range of conditions that appear qualitatively and quantitatively distinct. This lack of precise and biologically verifiable definition of illness presumably contributes to the inconsistencies extant within the literature pertaining to neurobiological abnormalities associated with MDD, the high-placebo effect observed in antidepressant treatment trials, and the plethora of psychotherapeutic and biological treatment options that reportedly exert antidepressant effects (Drevets and Todd 2005). Ultimately, the discovery of illness subtypes that are associated with specific biomarkers is expected to improve the effect size and reproducibility of research findings and therapeutic approaches.

Twin and other family studies indicate that genetic factors contribute substantially to the liability for developing MDD and BD, particularly in cases characterized by recurrent illness and early age-at-onset (Sullivan et al. 2000; Drevets and Todd 2005). The extant data suggest that the transmission of mood disorders involves complex interactions between multiple genes, each exerting relatively small effects on vulnerability. Several single nucleotide polymorphisms have been associated with increased risk for developing depression, although few of these findings are replicated. If confirmed in additional studies, these genetic markers would implicate neurotrophic, glutamatergic, cholinergic, serotonergic systems and intracellular signaling pathways in the pathogenesis of depression (Detera-Wadleigh and McMahon 2004). The genetic data also support a role for acquired factors in disease expression (Sullivan et al. 2000). For example, a geneenvironment interaction was described in which a functional polymorphism in the serotonin transporter promoter region increased the risk for developing MDE specifically within the context of stress (Caspi et al. 2003).

Stressful events are thought to constitute "acquired factors" that interact with genetic susceptibility in the development of mood disorders, although once the illness has been instantiated the potential links between stressors and subsequent MDE become progressively less evident (Drevets and Todd 2005). Early in the course of illness, MDE commonly appear to follow severe, stressful life events, whereas patients with recurrent MDD or BD commonly report that their pattern of depressive symptoms 
is unexplained by stressful life situations. Nevertheless, even within the context of chronic depression, stressful life events can severely and persistently worsen both the severity of the current MDE and the course of illness with respect to lowering the mood baseline to which patients return between episodes (many patients with MDD and BD develop progressive worsening of illness with failure to return to the premorbid level of mood and function). This downward trajectory is intensified by the problem that the psychosocial impairment associated with MDE often precipitates additional stressful events, such as job loss, scholastic failure and marital conflict or separation.

A variety of physiological and medical stressors also increase the risk for developing MDE. Notably the lifeevent most clearly associated with the development of depression and mania is the cessation of pregnancy, as the post-partum period constitutes the epoch of greatest risk for developing MDD or BD (Drevets and Todd 2005). Some neurological disorders, medical conditions and pharmacological substances also increase the risk for developing MDE, providing clues about the neurobiological systems in which dysfunction may induce depressive symptoms. For example, Parkinson's disease (PD) is associated with a twoto fourfold increase in the risk for developing MDE relative to other similarly disabling conditions. In about one-half of cases, the MDE onset precedes the onset of motor manifestations in PD (Santamaria et al. 1986). These findings led to hypotheses that degeneration of dopaminergic and/or serotonergic projections in PD impairs neural processes underlying reward processing and mood modulation, yielding depressive, anhedonic and anxiety symptoms.

Other medical diseases that increase the risk for depression or mania include endocrine disturbances (e.g., Cushing's syndrome), degenerative basal ganglia disorders (e.g., Huntington's or Wilson's Diseases), temporal lobe epilepsy, and structural lesions (tumors, infarcts, injury) involving the striatum, frontal lobe or mesiotemporal cortex (Drevets and Todd 2005). Pharmacologic agents that may precipitate MDE include drugs which induce endocrine or neurochemical changes similar to those found in primary mood disorders. For example, administration of corticosteroids (e.g., prednisone) or monoamine depleting agents (e.g., reserpine) result in neurochemical changes that resemble, respectively, the hypercortisolemia and reduced monoamineregic neurotransmitter function evident in MDD, and also can induce MDE in susceptible individuals (Drevets and Todd 2005).

Neural circuits affected by mood disorders

Evidence from neuroimaging, neuropathological, and lesion analysis studies implicates brain networks that normally regulate the evaluative, expressive and experiential aspects of emotional behavior in the pathophysiology of mood disorders (Phillips et al. 2003). These circuits include the limbic-cortical-striatal-pallidal-thalamic circuits (LCSPT), formed by connections between the orbital and medial prefrontal cortex (OMPFC), amygdala, hippocampal subiculum, ventromedial striatum, mediodorsal and midline thalamic nuclei and ventral pallidum (Ongür et al. 2003). The LCSPT circuits initially were related to emotional behavior on the basis of their anatomical connectivity with visceral control structures that mediate emotional expression, such as the hypothalamus and periaqueductal gray (PAG) (Nauta and Domesick 1984). They initially were implicated in the pathophysiology of depression by the observations that degenerative basal ganglia diseases and lesions of the striatum and orbital cortex increased the risk for developing MDE (Folstein et al. 1985). Because these conditions affect synaptic transmission through the LCSPT circuitry in diverse ways, it appears that dysfunction that alters transmission through these circuits in various ways can produce the pathological emotional symptoms encompassed by the MDE criteria (Drevets et al. 2004).

In addition to the LCSPT itself, neuroanatomical experiments in monkeys have shown that the orbital and medial prefrontal cortex is associated with two extended cortical circuits. One of these, which is mainly related to the central and lateral orbital areas ("the orbital prefrontal network"), includes sensory association areas such as visual associated areas in the inferior temporal cortex and somatic-sensory associated areas in the insula and frontal operculum, as well as olfactory and taste cortex (Ongür and Price 2000; Saleem et al. 2008). In addition to sensory integration, this system codes for affective characteristics of stimuli such as reward, aversion, and relative value. The other extended cortical system, which is primarily connected to the medial prefrontal cortex and a small region in the caudolateral orbital cortex (the "medial prefrontal network") includes the dorsomedial/ dorsal anterolateral prefrontal cortex (e.g., BA 9), the mid- and posterior cingulate cortex, a region in the anterior superior temporal gyrus and sulcus, and the entorhinal and posterior parahippocampal cortex (Kondo et al. 2005; Saleem et al. 2008). This system does not have substantial sensory connections, but has prominent connections with limbic structures and visceral control structures (hypothalamus and periaqueductal gray) (Ongür and Price 2000). This is the visceromotor system that is particularly involved in introspective functions such as mood and emotion, and visceral reactions to emotional stimuli. It closely resembles the "default system" that has been defined in human functional imaging studies as a system of areas that become deactivated from a resting "default" condition in most tasks that involve external attention to objects or events outside the individual (e.g., Gusnard et al. 2001; Fox et al. 2005). Compatible with this 
hypothesis, pharmacological, neurosurgical, and deep brain stimulation treatments for mood disorders appear to suppress pathological activity within the second visceromotor network structures such as the subgenual anterior cingulate cortex (sgACC), amygdala and ventral striatum (Drevets et al. 2002a; Mayberg et al. 2005; Drevets and Price 2005; Van Laere et al. 2006).

The extended visceromotor network also has been implicated by neuroimaging studies of pathological anxiety syndromes that occur comorbidly with MDD and BD (Charney and Drevets 2002). Although combinations of depressive and anxiety syndromes are classified by the current diagnostic nomenclature as a mood disorder plus a comorbid anxiety disorder, researchers expect that they reflect dysfunction from a single etiology, which alters emotion regulation within the visceromotor network. Consistent with this expectation, antidepressant drugs are the first-line treatments for both depressive and anxiety disorders.

\section{Brain structural abnormalities in mood disorders}

Patients with mood disorders show abnormalities of morphology or morphometry in many visceromotor network structures (Drevets and Price 2005). The extent or prevalence of these abnormalities depends partly on clinical characteristics such as age-at illness-onset, capacity for developing mania or psychosis, and evidence for familial aggregation of illness. For example, elderly MDD subjects with late-onset depression show an increased prevalence of neuroimaging correlates of cerebrovascular disease, relative both to age-matched, healthy controls and to elderly depressives with an early age-at depression-onset (Drevets et al. 2004). Similarly, MDD and BD cases who have either psychosis (delusions and/or hallucinations) or a late-life illness-onset show nonspecific signs of atrophy, such as lateral ventricle enlargement that are absent in early-onset, nonpsychotic MDD cases.

Nevertheless, early-onset, nonpsychotic MDD and BD cases also consistently show volumetric abnormalities that are localized to some PFC, cingulate and temporal lobe structures (Table 1). The most prominent volumetric abnormality reported to date has been a reduction in gray matter in the left anterior cingulate cortex (ACC) ventral to the corpus callosum genu (i.e., "subgenual") which is evident in MDD and BD with evidence of familial clustering or with psychotic features (Botteron et al. 2002; Coryell et al. 2005; Drevets et al. 1997; Hirayasu et al. 1999). Preliminary data suggest this volumetric reduction exists early in illness and in young adults at high familial risk for MDD (Botteron et al. 2002; Hirayasu et al. 1999).

Gray matter volume also is reduced in the orbital (BA 11, 47) and ventrolateral PFC (VLPFC; BA 45, 47) in MDD (Drevets and Price 2005) and BD (Lyoo et al. 2004)

Table 1 Neuroimaging and histopathological abnormalities evident in the visceromotor network (Ongür et al. 2003) in early-onset, recurrent major depressive disorder and/or bipolar disorder

\begin{tabular}{|c|c|c|c|c|}
\hline \multirow[t]{2}{*}{ Brain region } & \multirow{2}{*}{$\begin{array}{l}\text { Gray matter volume } \\
\text { Dep versus Con }\end{array}$} & \multirow{2}{*}{$\begin{array}{l}\text { Cell counts, cell markers } \\
\text { Dep versus Con }\end{array}$} & \multicolumn{2}{|c|}{ Glucose metabolism, CBF } \\
\hline & & & Dep versus Con & Dep versus Rem \\
\hline Dorsal medial/anterolateral PFC (BA9) & $\downarrow$ & $\downarrow$ & $\downarrow$ & $\downarrow$ \\
\hline Frontal polar C (BA 10) & & $\downarrow$ & $\downarrow$ & $\downarrow$ \\
\hline Subgenual anterior cingulate $\mathrm{C}$ & $\downarrow$ & $\downarrow$ & $\downarrow / \downarrow^{\mathrm{a}}$ & $\downarrow$ \\
\hline Pregenual anterior cingulate $\mathrm{C}$ & $\downarrow$ & $\downarrow$ & $\downarrow$ & $\downarrow$ \\
\hline Orbital C/ventrolateral PFC & $\downarrow$ & $\downarrow$ & $\downarrow$ & $\downarrow$ \\
\hline Posterior cingulate & $\downarrow$ & & $\downarrow$ & $\downarrow$ \\
\hline Parahippocampal C & $\downarrow$ & $\downarrow \mathrm{BD}$ & $\downarrow$ & $\downarrow$ \\
\hline Amygdala & $\downarrow / \uparrow^{\mathrm{b}}$ & $\downarrow \mathrm{MDD}$ & $\downarrow$ & $\downarrow$ \\
\hline Ventromedial striatum & $\downarrow$ & & $\downarrow$ & $\downarrow$ \\
\hline Hippocampus & $\downarrow$ & $\downarrow \mathrm{BD}$ & n.s. & n.s. \\
\hline Superior temporal G/temporopolar C & $\downarrow$ & & & $\downarrow$ \\
\hline Medial thalamus & & & $\downarrow$ & $\downarrow$ \\
\hline
\end{tabular}

\footnotetext{
${ }^{a}$ In the subgenual anterior cingulate cortex the apparent reduction in CBF and metabolism in PET images of depressed subjects is thought to be accounted for by the reduction in tissue volume in the corresponding cortex, as after partial volume correction for the reduction in gray matter the metabolism appears increased relative to controls

$\mathrm{b}$ The literature is in disagreement with respect to the amygdala volume in mood disorders. In MDD, the volume appears reduced in cases whose MDE show a chronic or intermit course

$C$ cortex, Dep versus Con unmedicated depressives versus healthy controls, Dep versus Rem unmedicated depressives versus themselves in either the medicated or unmedicated remitted phases, $G$ gyrus, n.s. differences generally not significant, $P F C$ prefrontal cortex

Empty cells indicate insufficient data. Modified from (Drevets 2007)
} 


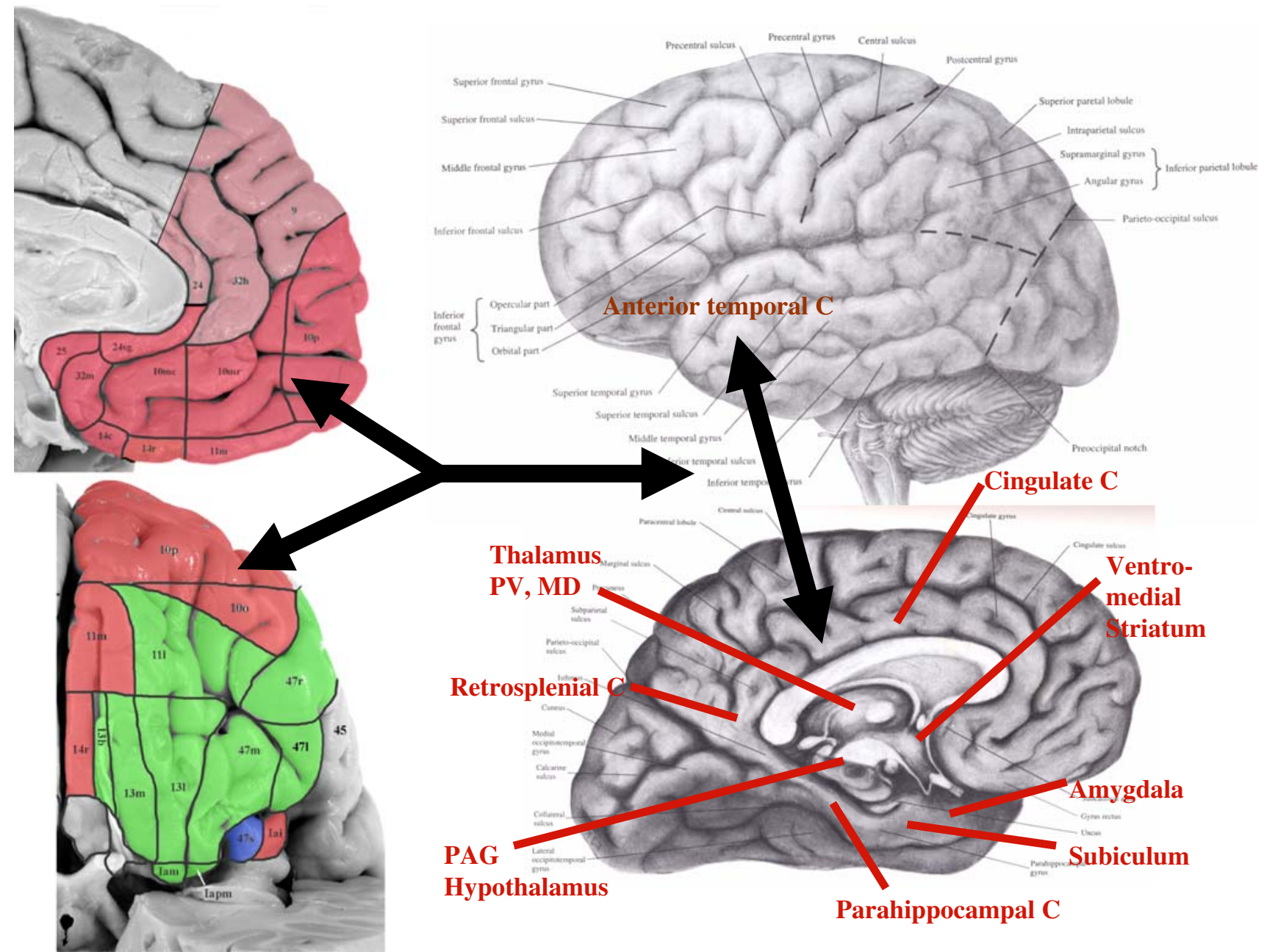

Fig. 1 Regions and anatomical projections that form the extended visceromotor network. The cytoarchitectonic subdivisions of the human orbital (upper left) and medial prefrontal cortical surfaces (lower left) are distinguished here as being predominantly in the visceromotor (pink) or sensory (green) networks described in (Ongür and Price 2000). These portions of the figure are modified from Ongür et al. (2003), with the lighter shade of pink reflecting more recent work regarding the portions of the medial wall that share the connectional features of the visceromotor network. The area shown in blue, the sulcal portion of BA 47 [47 s; which corresponds to orbital portion of Walker area 12 (i.e., 12o) of the monkey; see Fig. 2], shares features of both the visceromotor and sensory networks. This

the frontal polar/dorsal anterolateral PFC (BA 9, 10) in MDD (Drevets et al. 2004), and the posterior cingulate cortex and superior temporal gyrus in BD (Nugent et al. 2006). In BD the peak difference in gray matter loss in the lateral orbital cortex was found in the sulcal BA47 cortex (Nugent et al. 2006), a region that appears to correspond to an area which Ongür et al. proposed is related to the MPFC as part of the medial prefrontal network (Figs. 1, 2). In addition, white matter is decreased in the genu of the corpus callosum in both adults with MDD or BD and their high-risk child and adolescent offspring (particularly in region and the anterior (agranular) insula $(I a)$ continue into the lateral cortical wall, so are better viewed in the coronal sections shown in Ongür et al. 2003). The major structures that receive efferent projections from the visceromotor component of the OMPFC are indicated on the right panel over the brain diagram. These include the posterior cingulate cortex, the anterior temporal cortex, and the entorhinal and parahippocampal cortex, all of which are implicated in the "default system" (Hsu and Price 2007; Kondo et al. 2003, 2005; Price 2007; Saleem et al. 2007, 2008). $C$ cortex, $M D$ mediodorsal nucleus of the thalamus, $P A G$ periaqueductal gray; $P V$ periventricular nucleus of the thalamus

females), and in the splenium of the corpus callosum in adults with MDD or BD.

Some studies also reported reductions in hippocampal volume in MDD, ranging in magnitude from 8 to $19 \%$, although other studies did not replicate these differences (Drevets et al. 2004). The discrepant results across studies may reflect clinical heterogeneity as one study reported that reduced hippocampal volume was limited to depressed women who suffered early-life trauma, Vythilingam et al. (2002) and others reported that hippocampal volume correlated inversely with time spent depressed (e.g., Sheline 

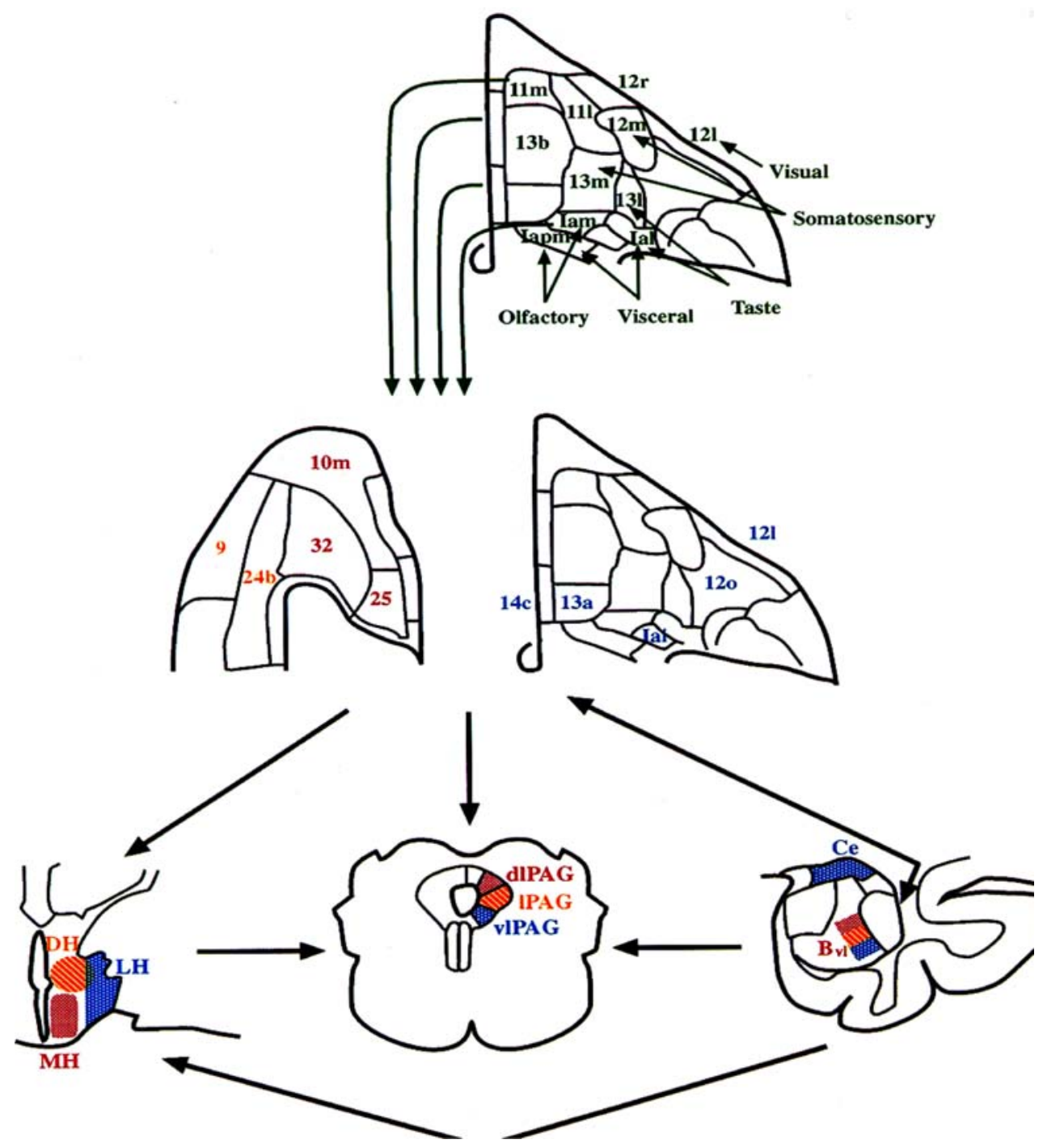

Fig. 2 Architectonic maps of the orbital (upper and right-center panels) and medial prefrontal cortical surfaces (left-center panel) of the macaque brain, modified from Carmichael and Price (1994). The upper panel shows the areas hypothesized to form the "sensory" network of the orbital cortex based upon their afferent connections with various sensory domains, which are indicated next to each set of regions. This sensory network projects into the "visceromotor" network (middle panel). This latter network shares extensive, reciprocal connections with the amygdala, periaqueductal gray and hypothalamus (shown in coronal sections at the lower right, center and left, respectively), areas which play major roles in organizing or

et al. 2003). In addition, preliminary evidence suggests that volumetric reductions in the anterior subiculum/ventral $\mathrm{CA} 1$ region appeared specific to $\mathrm{BD}$.

Elucidating the effect of such clinical variables may also prove helpful in resolving disagreements in the literature regarding the existence of morphometric abnormalities in the amygdala and striatum. In the amygdala, the volume has been reported to be increased in some studies but decreased in others in depressives relative to controls (Drevets et al. 2004). In the striatum Husain et al. (1991) mediating the endocrine, autonomic, and behavioral aspects of emotional behavior. The specific cytoarchitectonic areas of the visceromotor component of the orbitomedial PFC are color coded according to the specific nuclei of the amygdala and hypothalamus or the column of the PAG to which they predominantly project (Carmichael and Price 1995; Ongür and Price 1998; Floyd et al. 2000, 2001). $B v l$ ventrolateral part of the basal nucleus of the amygdala, $\mathrm{Ce}$ central nucleus of the amygdala, $\mathrm{DH}$ dorsal hypothalamic area, $L H$ lateral hypothalamic area, $M H$ medial hypothalamic area; dIPAG, IPAG, vlPAG dorsolateral, lateral, and ventrolateral columns of the PAG, respectively

reported that the putamen was smaller in depressives than controls, and Krishnan et al. (1992) found a smaller caudate nucleus volume in depressives than controls. In a sample limited to elderly depressives, Krishnan et al. (1993) also reported smaller putamen and caudate volumes relative to controls. These findings were consistent with the post mortem study of Baumann et al. (1999), which found that caudate and accumbens area volumes were markedly decreased in both MDD and BD samples relative to control samples. Nevertheless, other studies found no significant 
difference in stiatal or pallidal volumes between younger MDD subjects and controls (Drevets et al. 2004).

Conventional antidepressant drug treatment and symptom remission do not appear to alter the reductions in gray matter volume in the sgACC (Drevets et al. 1997), but may arrest further gray matter decrements in the hippocampus (Sheline et al. 2003). However, chronic lithium treatment, which exerts robust neurotrophic effects in animal models, has been associated with increasing gray matter volume toward normal in treatment responders in the sgACC and other PFC areas (Moore et al. 2008).

Finally, consistent with evidence that the hypothalamicpituitary-adrenal axis function is elevated in some mooddisordered subgroups, the pituitary and adrenal glands are reportedly enlarged in MDD. For example Krishnan et al. (1991) showed that MRI-based measures of cross-sectional area and volume of the pituitary were increased (by 34 and $41 \%$, respectively) in depressives versus controls. This observation is consistent with evidence that the adrenal gland is also abnormally enlarged in MDD (reviewed in Drevets et al. 2004), putatively due to chronically elevated stimulation of the adrenal cortex by ACTH.

\section{Neurophysiological imaging abnormalities in mood disorders}

Many of the regions where structural abnormalities are apparent in mood disorders also contain abnormalities of cerebral blood flow $(\mathrm{CBF})$ and glucose metabolism (Table 1; Fig. 3). In most of these structures, and particularly those which form the extended visceromotor network (see above), the basal activity appears increased in the depressed phase relative to the remitted phase of MDD. This pattern of differences has been demonstrated by longitudinal studies of depressed patients imaged before versus after treatment (e.g., Drevets et al. 2002a), or of remitted patients scanned before versus during depressive relapse (e.g., Neumeister et al. 2004).

Nevertheless, the reduction in gray matter volume in some structures is sufficiently prominent to produce partial volume effects in functional brain images due to their relatively low spatial resolution, yielding complex relationships between physiological measures and depression severity. For example, relative to controls, depressed MDD and BD subjects show metabolic activity that appears reduced in the sgACC (Drevets et al. 1997). However, when this volumetric deficit is taken into account by correcting the metabolic data for the partial volume averaging effect associated with the corresponding gray matter reduction (which have ranged in magnitude from about 20 to $50 \%$ across studies of MDD and $\mathrm{BD})$, metabolism instead appears increased in the sgACC in the unmedicated-depressed phase and normal in the medicated-remitted phase (Drevets and Price 2005). The volumetric reductions in the orbital cortex and VLPFC may also contribute to the complexity of relationships observed between metabolism and illness severity, as metabolism appears elevated in depressed samples of mild-to-moderate severity, but reduced in more severe, treatment refractory cases (Drevets et al. 1992; Ketter et al. 2001).

Although the pattern of activity in the extended visceromotor network generally is one in which metabolism is elevated during the depressed relative to the remitted phases, the relationship between physiological activity and symptom severity differs in valence across some structures, compatible with preclinical evidence that distinct MPFC structures are involved in opponent processes with respect to emotional behavior (Vidal-Gonzalez et al. 2006). Regions where metabolism correlates positively with depression severity include the amygdala, sgACC and ventromedial frontal polar cortex (Drevets and Price 2005; Hasler et al. 2008). Metabolism and flow decrease in these regions as a common functional anatomical effect of both antidepressant drug treatment and deep brain stimulation of the sgACC or anterior capsule (Mayberg et al. 2005; Drevets et al. 2002a; Van Laere et al. 2006; Mayberg et al. 1999), despite the diverse mechanisms underlying these treatments. Conversely, in recovered MDD cases who experience depressive relapse under experimental conditions involving serotonin or catecholamine depletion, the metabolic activity increases in these regions as the depressive symptoms return (Neumeister et al. 2004; Hasler et al. 2008) although the elevation of left amygdala activity during serotonin depletion-induced relapse was limited to homozygotes for the long allele of the serotonin transporter promoter region length polymorphism (5HTT LPR) (Neumeister et al. 2006b).

In some regions abnormalities of physiological activity appear specific to clinically defined subtypes of mood disorders. For example, in the amygdala, abnormal elevations of resting metabolism can be seen in depressed samples categorized as having BD, familial pure depressive disease (FPDD), MDD-melancholic type, or MDD which is responsive to a night of total sleep deprivation (reviewed in Drevets 2001). In such cases, amygdala metabolism decreases toward normative levels during effective antidepressant treatment (Drevets et al. 2002a).

In contrast, a broader range of depressed subjects appears to show abnormal hemodynamic responses in the amygdala to emotional stimuli (as detailed below under the section, Emotional Processing Bias). For example, the hemodynamic responses of the left amygdala were smaller in magnitude in depressed children (Thomas et al. 2001) and adults (Drevets 2003) while viewing fearful faces, and prolonged in duration in depressed adults while viewing sad words (Siegle et al. 2002). In contrast, MDD cases showed increased hemodynamic activity relative to controls in the left amygdala in response to fearful (Sheline et al. 2001) 

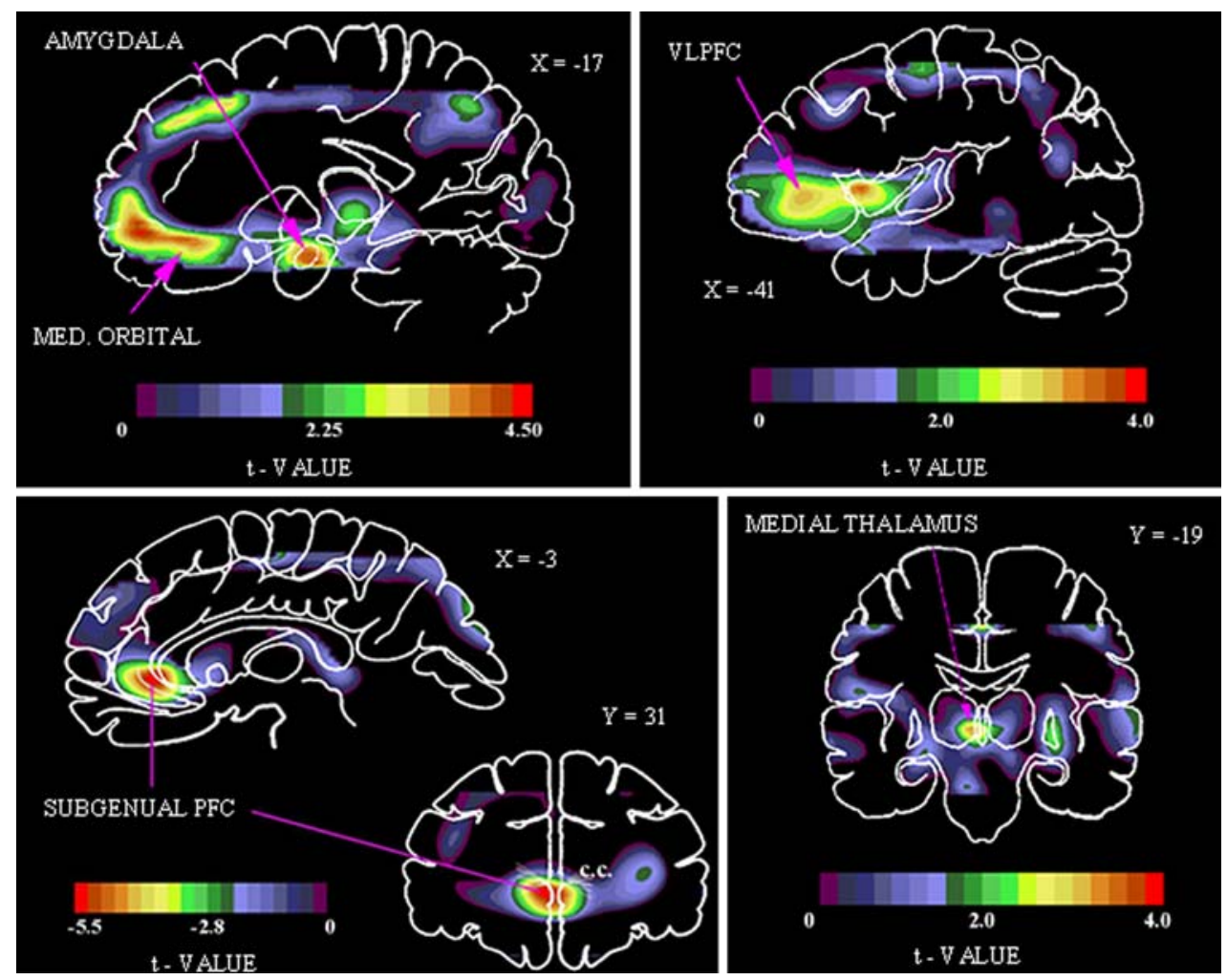

Fig. 3 Areas of abnormally increased physiological activity in familial MDD shown in images of unpaired $t$ values, which were computed using a statistical parametric mapping approach to compare activity between depressives and controls (Drevets et al. 1992, 1997). Upper left the positive $t$ values in this sagittal section located $17 \mathrm{~mm}$ left of midline $(X=-17)$ show areas were CBF is increased in depressives versus controls in the amygdala and medial (MED) orbital cortex (reproduced from Price et al. 1996). Upper right positive $t$ values in a sagittal section $41 \mathrm{~mm}$ left of midline $(X=-41)$ show areas where $\mathrm{CBF}$ is increased in the depressives in the left ventrolateral PFC (VLPFC), lateral orbitofrontal $\mathrm{C}$, and anterior insula (reproduced from Drevets et al. 2004). Lower right positive $t$

and sad faces (Fu et al. 2004) presented using backwardmasking technique (such that subjects were explicitly aware only of having seen a face with a neutral expression). This exaggerated left amygdala response was attenuated following successful antidepressant pharmacotherapy.

In the accumbens area, medial thalamus and posterior cingulate cortex metabolism is abnormally elevated in the depressed phase of MDD and BD (Drevets et al. 2002a, 2004). In fMRI studies the regional hemodynamic responses are attenuated in the ventral striatum in reward-processing tasks, and in both the ventral striatum and the posterior cingulate in tasks involving negative feedback (e.g., Knutson et al. 2007).

\section{Neuropathological correlations in mood disorders}

Most of the regions where MRI studies demonstrated volumetric abnormalities in mood disorders also have been values in a coronal section located $19 \mathrm{~mm}$ posterior to the anterior commissure $(Y=-19)$ shows an area where CBF is increased in the depressives in the left medial thalamus (reproduced from Drevets and Todd 2005). Lower left coronal (31 $\mathrm{mm}$ anterior to the anterior commissure; $Y=31$ ) and sagittal (3 mm left of midline; $X=-3$ ) sections showing negative voxel $t$ values where glucose metabolism is decreased in depressives relative to controls. The reduction in activity in this prefrontal cortex $(P F C)$ region located in the anterior cingulate gyrus ventral to the genu of the corpus callosum (i.e., subgenual) appeared to be accounted for by a corresponding reduction in cortex volume (Table 1; reproduced from Drevets et al. 1997). Anterior or left is to left

shown to contain histopathological changes or gray matter volumetric reductions in post mortem studies of MDD and BD. For example, reductions of gray matter volume, thickness or wet weight have been reported in the subgenual ACC, posterolateral orbital cortex, and ventral striatum in MDD and/or BD subjects relative to controls (Baumann et al. 1999; Bowen et al. 1989; Ongür et al. 1998; Rajkowska et al. 1999), and greater decrements in volume following fixation (implying a deficit in the neuropil) were demonstrated in the hippocampus in MDD (Stockmeier et al. 2004). The histopathological correlates of these abnormalities included reductions in glial cells with no equivalent loss of neurons, reductions in synapses or synaptic proteins, elevations in neuronal density, and reductions in neuronal size in MDD and/or BD samples (Rajkowska et al. 1999; Ongür et al. 1998; Cotter et al. 2001a, 2002; Eastwood and Harrison 2000, 2001; Uranova et al. 2004). Reductions in glial cell counts and density, 
and/or glia-to-neuron ratios additionally were found in MDD subjects versus controls in the pregenual ACC (pgACC [BA24]) (Cotter et al. 2001a), the dorsal anterolateral PFC (BA9) (Cotter et al. 2002; Uranova et al. 2004) and the amygdala (Bowley et al. 2002; Hamidi et al. 2004). Finally, the mean size of neurons was reduced in the dorsal anterolateral PFC (BA 9) in MDD subjects relative to controls (Rajkowska et al. 1999), and the density of nonpyramidal neurons was decreased in the ACC and hippocampus in BD (Benes et al. 2001; Todtenkopf et al. 2005), and in the dorsal anterolateral PFC (BA9) of MDD (Rajkowska et al. 2007). Reductions in synapses and synaptic proteins were evident in BD subjects in the hippocampal subiculum/ventral CA1 region (Eastwood and Harrison 2000; Rosoklija et al. 2000), and the expression of multiple genes involved in axonal growth/synaptic function was reduced in the middle temporal cortex in MDD subjects (Aston et al. 2005). Notably, in several of these studies, the decreases were largely accounted for by differences in the left hemisphere (e.g., Bowley et al. 2002; Hamidi et al. 2004; Bowen et al. 1989; Ongür et al. 1998).

The glial type that specifically differed between MDD and control samples in many of these studies was the oligodendrocyte (e.g., Uranova et al. 2004; Hamidi et al. 2004). Oligodendroglia are best characterized for their role in myelination, and the reduction in oligodendrocytes may conceivably arise secondary to an effect on myelin, either through demyelination, abnormal development, or atrophy in the number of myelinated axons. Notably, the myelin basic protein concentration was found to be decreased in the frontal polar cortex (BA 10) (Honer et al. 1999), and the expression of genes related to oligodendrocyte function (i.e., genes which encoded structural components of myelin, enzymes involved in the synthesis of myelin constituents or in the regulation of myelin formation, transcription factors regulating other myelination-related genes, or factors involved in oligodendrocyte differentiation) was decreased in the middle temporal gyrus in MDD subjects relative to controls (Aston et al. 2005). Compatible with these data, the myelin staining was decreased in the deep white matter of the dorsolateral PFC in MDD and BD subjects (Regenold et al. 2007), and the white matter volume of the genual and splenial portions of the corpus callosum were abnormally reduced in MDD and BD (e.g., Brambilla et al. 2004). These regions of the corpus callosum also were smaller in child and adolescent offspring of women with MDD who had not yet developed a mood disorder, relative to age-matched controls, suggesting that the reduction in white matter in MDD reflects a developmental defect that exists prior to illness onset (Martinez et al. 2002). These observations are compatible with evidence that the glial cell loss in mood disorders includes a reduction in myelinating oligodendrocytes.
Another observation that supports this hypothesis is that several reports of deficits in glia in the cerebral cortex depended upon laminar analysis, with the greatest effects in layers III, V, and VI (Cotter et al. 2001a, 2002; Rajkowska et al. 1999, 2001; Uranova et al. 2004; Vostrikov et al. 2007). The intracortical plexuses of myelinated fibers known as "Bands of Baillarger" are generally concentrated in layers III and V. The size of these plexuses varies across cortical areas, so if the oligodendrocytes related to these plexuses were affected, different areas would be expected to show greater or lesser deficits. Layer VI in particular has a relatively large component of myelinated fibers running between the gray and white matter.

Finally, satellite oligodendrocytes also were implicated in the pathophysiology of mood disorders by electron microscopic study of the PFC in BD which revealed decreased nuclear size, clumping of chromatin and other types of damage to satellite oligodendrocytes, including indications of both apoptotic and necrotic degeneration (Uranova et al. 2001; Vostrikov et al. 2007). Satellite oligodendrocytes are immunohistochemically reactive for glutamine synthetase, suggesting they function like astrocytes to take up synaptically released glutamate for conversion to glutamine and cycling back into neurons (D’Amelio et al. 1990).

In other brain regions, reductions in astroglia have been reported by post mortem studies of mood disorders. In the frontal cortex one study found that four forms of the astrocytic product, glial fibrillary acidic protein (GFAP), were decreased in mood-disordered subjects relative to controls, although it was not determined whether this decrement reflected a reduction in the astrocyte density or the GFAP expression (Johnston-Wilson et al. 2000). However, another study which used immunohistochemical staining for GFAP did not find significant differences in cortical astrocytes between controls, and MDD or BD cases (Webster et al. 2001). Other studies also did not find differences in GFAP between mood-disorder cases and controls (reviewed in Cotter et al. 2001b).

Factors that may conceivably contribute to a loss of oligodendroglia in mood disorders include the elevated glucocorticoid secretion and glutamatergic transmission evident during depression and mania. Glucocorticoids affect both glia and neurons (Cheng and de Vellis 2000) and elevated glucocorticoid concentrations and repeated stress decrease the proliferation of oligodendrocyte precursors (Alonso 2000; Banasr and Duman 2007). Moreover, oligodendrocytes express AMPA and kainate type glutamate receptors, and are sensitive to excitotoxic damage from excess glutamate (Dewar et al. 2003; Matute et al. 1997; McDonald et al. 1998). The targeted nature of the reductions in gray matter volume and glial cells to specific areas of the limbic-cortical circuits that show 
increased glucose metabolism during depressive episodes is noteworthy given the evidence reviewed below that the glucose metabolic signal is dominated by glutamatergic transmission.

\section{Correlations with rodent models of chronic and repeated stress}

The putative role of stress in precipitating MDE has promoted the development of rodent stress models to facilitate investigations of the neurobiological correlates of human mood disorders. In regions that appear homologous to the areas where gray matter reductions are evident in depressed humans (i.e., medial PFC, hippocampus), repeated stress results in dendritic atrophy and reductions in glial cell counts or proliferation in rodents (Banasr and Duman 2007; Czeh et al. 2005; McEwen and Magarinos 2001; Wellman 2001; Radley et al. 2008; Conrad et al. 1999). In the basolateral amygdala (BLA), chronic, unpredictable stress also produced dendritic atrophy, but chronic immobilization stress instead increased dendritic branching (Banasr and Duman 2007; Vyas et al. 2002, 2003), suggesting that the effect of chronic immobilization stress on dendritic remodeling is regionally specific (Conrad et al. 1999).

Dendritic atrophy presumably would be reflected by a decrease the volume of the neuropil, which occupies most of the gray matter volume. The similarities between the histopathogical changes that accompany stress-induced dendritic atrophy in rats and those found in humans suffering from depression thus have led to hypotheses that homologous processes underlie the reductions in gray matter volume in hippocampal and PFC structures in MDD and BD (McEwen and Magarinos 2001). In rats the stressinduced dendritic atrophy in the medial PFC was associated with impaired modulation (i.e., extinction) of behavioral responses to fear-conditioned stimuli (Izquierdo et al. 2006). The observation that such changes influence emotional expression are noteworthy in light of evidence that volumetric reductions in humans with mood disorders are associated with more severe and chronic pathological mood episodes. Moreover, when rats were subjected to repeated stress beyond 4 weeks, the dendritic atrophy could be reversed by lithium administration (McEwen and Magarinos 2001). The differential effects of these drugs on dendritic atrophy in stressed rats thus resemble their effects on sgACC volume in humans with BD (Moore et al. 2008; Drevets et al. 1997; Drevets and Savitz 2008).

These dendritic reshaping processes depend on interactions between the increased $N$-methyl-D-aspartate (NMDA) receptor stimulation and glucocorticoid secretion associated with repeated stress (McEwen and Magarinos 2001). Elevations of glutamate transmission and cortisol secretion in mood disorders also may contribute to reductions in gray matter volume and synaptic markers by inducing dendritic atrophy in some brain structures, as the depressive subtypes (e.g., BD, FPDD) who show regional reductions in gray matter volume also show evidence of increased cortisol secretion and glutamate transmission (Drevets et al. 2002b). Subjects with FPDD or familial BD also show elevations of glucose metabolism, which largely reflects glutamate transmission (see below), in the medial and orbital PFC, amygdala, ventral striatum, and cingulate cortex regions that show reductions in gray matter volume and cellular elements. The findings that gray matter reductions appear to occur specifically in regions that show hypermetabolism during depression thus raise the possibility that excitatory amino acid transmission plays a role in the neuropathology of mood disorders. In many of the regions where glucose metabolism is increased in the depressed phase relative to the remitted phase, reductions in cortex volume and/or histopathological changes have been found in in vivo MRI studies and/or post mortem studies of MDD and/or BD.

\section{Neurochemical systems implicated in depression}

Of the neurochemical systems that modulate neural transmission within the visceromotor network, mood disorders have been associated with abnormalities of serotonergic, dopaminergic, noradrenergic, cholinergic, glutamatergic, GABA-ergic, glucocorticoid and peptidergic [e.g., corticotrophin releasing factor (CRF)] function. Agents that impact monoamineregic neurotransmitter systems particularly have received attention because most antidepressant drugs exert their primary pharmacological actions through these systems. However, the delayed onset of antidepressant effects (generally lagging the initiation of treatment by about 3 weeks) suggest that secondary mechanisms involving changes in gene expression and/or synaptic plasticity may underlie the therapeutic mechanisms of these drugs. The neuropharmacological mechanisms hypothesized to serve as final common pathways for antidepressant responses include: (1) increases in the gene expression of brain derived neurotrophic factor (BDNF) and other neurotrophic/neuroprotective factors in the hippocampus and PFC (Manji et al. 2001; Santarelli et al. 2003); (2) enhancement of postsynaptic serotonin type 1A $\left(5-\mathrm{HT}_{1 \mathrm{~A}}\right)$ receptor function (Haddjeri et al. 1998; Chaput et al. 1991); (3) attenuation of the sensitivity or transmission of NMDA-glutamatergic receptors (Krystal et al. 2002; Paul and Skolnick 2003).

\section{Glutamatergic and GABA-ergic systems}

The function of glutamate and $\gamma$-amino-butyric acid (GABA) appears altered in mood disorders. Early studies 
reported that GABA concentrations were abnormally decreased in the plasma and cerebrospinal fluid (CSF) in MDD subjects (reviewed in Hasler et al. 2007). In contrast, post mortem studies of the NMDA receptor complex in suicide victims found evidence suggesting that glutamatergic transmission had been increased in the PFC antemortem, and implicated disturbances in glutamate metabolism, NMDA, and mGluR1,5 receptors in depression and suicide (Paul and Skolnick 2003). Moreover, antidepressant and mood-stabilizing drugs which have diverse primary pharmacological actions generally reduce NMDA receptor sensitivity and/or transmission, and many of these agents increase GABA levels or transmission (Krystal et al. 2002; Paul and Skolnick 2003).

Elevated glutamatergic function is thought to support the neurophysiological activation of visceromotor circuits in depression. The anatomical projections between the MPFC, striatum and amygdala implicated in mood disorders are formed by predominantly excitatory projections in rats and monkeys (Ongür et al. 2003; Ongür and Price 2000). Since cerebral glucose metabolism largely reflects the energetic requirements associated with glutamatergic transmission (Shulman et al. 2004), the elevated metabolism evident in limbic-thalamo-cortical circuits in depression implies that glutamatergic transmission is increased in these circuits (Drevets et al. 1992; Swerdlow and Koob 1987). During effective antidepressant drug or electroconvulsive therapy, metabolic activity decreases in these regions (Table 1; reviewed in Drevets et al. 2002a, 2004), compatible with evidence that these treatments result in desensitization of NMDA receptors in the PFC (Paul and Skolnick 2003). As described above, elevated glutamatergic transmission within discrete anatomical circuits also may explain the targeted nature of gray matter changes within mood disorders (e.g., affecting left more than right sgACC) (McEwen and Magarinos 2001; Drevets and Price 2005).

Magnetic resonance spectroscopic (MRS) studies of MDD also demonstrate abnormalities of glutamate (measured together with cerebral glutamine as the combined "Glx" peak in the MRS spectra) and GABA concentrations in MDD. These spectra reflect the combined intracellular and extracellular pools of glutamate, glutamine and GABA, but are dominated overwhelmingly by the intracellular pools. Depressed MDD subjects show abnormally reduced GABA levels in both, the dorsomedial/dorsal anterolateral PFC and the occipital cortex (Sanacora et al. 1999; Hasler et al. 2007). The majority of the GABA pool exists within GABAergic neurons, so the reduction in GABA in the dorsal anterolateral PFC is compatible with the report of reduced GABA-ergic neurons in this region (BA9) in MDD (Rajkowska et al. 2007).
Depressed subjects also show abnormally reduced Glx levels in the dorsomedial/dorsal anterolateral and ventromedial PFC regions where histopathological and neurophysiological abnormalities are evident in depression (Drevets and Price 2005). Since the Glx measure reflects the intracellular glutamate and glutamine pools, the abnormal reductions in Glx concentrations would be compatible with the reductions in glial cells found post mortem in the same regions in MDD, as glia play prominent roles in glutamate-glutamine cycling.

\section{Glucocorticoid system}

The hypothalamic-pituitary-adrenocortical (HPA) axis appears overactive in some patients with depression. Severe depression is associated with hypersecretion of cortisol, pituitary and adrenal gland enlargement, and CSF-CRF levels that are increased to an extent that is inappropriate to the plasma cortisol concentrations, implying that both deficits in negative feedback systems and/or excessive central stimulation of the secretion of $\mathrm{CRF}$ and/or other ACTH secretagogues exists in mood disorders (Gold and Chrousos 2002; Drevets et al. 2004; Swaab et al. 2005; Carroll et al. 2007). Depressed subjects also show blunted ACTH responses to CRF in vivo, and reduced CRF receptor density in the PFC and increased corticotrophic cell size and mRNA levels in the pituitary post mortem, indicating chronic activation of the HPA axis (Gold and Chrousos 2002; Lopez et al. 1992; Swaab et al. 2005). Finally, some depressives show reduced sensitivity to glucocorticoid "fast feedback" (Young et al. 1993) and/ or to dexamethasone negative feedback (Carroll et al. 1981), although these findings depend upon depressive subtype, being most common in melancholic and psychotic cases (Carroll et al. 2007). During successful treatment, serum cortisol and CSF levels of CRF normalize, and cortisol secretion becomes suppressible by dexamethasone (Musselman and Nemeroff 1993). The chronic elevation of cortisol secretion in some depressive subtypes is thought to contribute to mitochondrial dysfunction, neuropathological changes, elevated body temperature, premature osteoporosis and aging, and other medical morbidity in individuals suffering from mood disorders (McEwen and Magarinos 2001; Gold et al. 2002).

\section{Serotonergic system}

The central serotonin (5-HT) system has received particular attention in depression research because selective serotonin reuptake inhibitors (SSRI) exert antidepressant effects, and most other antidepressant drugs also increase 5-HT transmission. This effect of antidepressant drugs may augment an endogenous elevation of serotonin release 
during the stress associated with depression, analogous to the enhanced 5-HT transmission that occurs in some brain regions during stress in rodents (Cannon et al. 2007; Barton et al. 2008; Inoue et al. 1994). Enhancement of 5-HT transmission in MDD also may compensate for the abnormalities in density and sensitivity of some 5-HT receptor subtypes evidenced by post mortem, neuroimaging and pharmacological challenge studies of depression (Stockmeier 2003). For example, postsynaptic 5-HT $1 \mathrm{~A}$ receptor binding or mRNA expression is decreased in the insula, cingulate, parieto-occipital and orbital/ventrolateral prefrontal cortices in most studies of MDD and BD (e.g., Drevets et al. 1999, 2007; Sargent et al. 2000; Lopez et al. 1998), and the thermic and adrenocorticotropin/cortisol responses to $5-\mathrm{HT}_{1 \mathrm{~A}}$ receptor agonist challenge are blunted in MDD (Lesch 1992). Conversely, chronic administration of antidepressant drugs with diverse primary pharmacological actions enhances post-synaptic 5- $\mathrm{HT}_{1 \mathrm{~A}}$ receptor function (Haddjeri et al. 1998; Chaput et al. 1991). Compatible with hypotheses that enhancement of 5-HT transmission is relevant to maintaining remission in MDD, about one-half of remitted MDD subjects who are unmedicated or are being treated with SSRI agents experience depressive relapse under tryptophan depletion (which putatively decreases central serotonergic function; e.g., Neumeister et al. (2004).

It remains unclear whether the reduction in $5-\mathrm{HT}_{1 \mathrm{~A}}$ receptor function and expression in mood disorders constitutes a neurodevelopmental or an acquired abnormality. This issue is of interest because interruption of $5-\mathrm{HT}_{1 \mathrm{~A}}$ receptor function during neurodevelopment persistently alters the function of emotion modulating systems in genetically engineered mice (Gross et al. 2002). Nevertheless, the reduction in $5-\mathrm{HT}_{1 \mathrm{~A}}$ receptor binding and mRNA expression in depression may arise secondarily to cortisol hypersecretion (Lopez et al. 1998), as the 5- $\mathrm{HT}_{1 \mathrm{~A}}$ receptor mRNA expression and density are under tonic inhibition by glucocorticoid receptor (GR) stimulation. In experimental animals the increased CORT secretion during chronic or repeated stress results in decreased 5- $\mathrm{HT}_{1 \mathrm{~A}}$ receptor mRNA expression and density (Lopez et al. 1998; Flugge 1995). Moreover, the mood and anxiety disordered subgroups with reduced $5-\mathrm{HT}_{1 \mathrm{~A}}$ receptor binding appear limited to those who manifest evidence of a diathesis to hypersecrete cortisol (e.g., under stressed conditions) (Lopez et al. 1998; Drevets et al. 1999, 2007).

Altered serotonin transporter (5-HTT) function also is thought to play a role in the pathophysiology of MDE (Cannon et al. 2006b; Stockmeier 2003). Multiple genetic polymorphisms involving 5-HTT regulatory sites reportedly increase the vulnerability for developing mood disorders (reviewed in Cannon et al. 2007). For example, the common "short" allele of the functional 5-HTT LPR polymorphism increases the vulnerability for developing MDD within the context of stressful life events (Caspi et al. 2003).

\section{Catecholaminergic systems}

The central dopaminergic and noradrenergic systems also have been implicated in the pathophysiology of depression and the mechanisms of antidepressant drugs (Nutt 2006). Administration of reserpine or $\alpha$-methyl-para-tyrosine, which reduces the availability of brain catecholamines, induces depressive syndromes in vulnerable individuals (e.g., Hasler et al. 2008). Conversely, norepinephrine (NE) reuptake inhibitors, dopamine (DA) reuptake inhibitors (i.e., nomifensine) and dopamine receptor agonists (e.g., pramipexole) exert antidepressant effects in placebo-controlled studies (Willner 1995; Zarate et al. 2004). In MDD the CSF and jugular vein plasma levels of the DA metabolite, homovanillic acid, are abnormally decreased, consistent with decreased DA turnover (Willner 1995; Lambert et al. 2000). In contrast, the levels of NE metabolite concentrations were decreased in some (e.g., Lambert et al. 2000), but increased in other studies (e.g., Veith et al. 1994). Neuroimaging studies of MDD showed reduced striatal DA transporter binding and $\left[{ }^{11} \mathrm{C}\right] \mathrm{L}-\mathrm{DOPA}$ uptake across the blood-brain-barrier, consistent with reduced DA neurotransmission (Nutt 2006). Finally, degeneration of DA neurons in Parkinson's Disease is associated with increased vulnerability for developing a major depressive syndrome (Santamaria et al. 1986).

The mesolimbic DA projections from the ventral tegmental area (VTA) to the nucleus accumbens shell and the medial PFC play major roles in learning associations between operant behaviors or sensory stimuli and reward, and in mediating the reinforcing properties of drugs of abuse and natural rewards such as food and sex (Nestler and Carlezon 2006). Thus the evidence suggesting that DA release is reduced in depression gave rise to hypotheses that a reduction in mesolimbic DA function underlies the anhedonia, amotivation and psychomotor slowing associated with MDE (Swerdlow and Koob 1987; Nestler and Carlezon 2006). A preliminary study which used PET measures of [C-11]raclopride binding to DA D2/D3 receptors to assess endogenous DA release found that depressed subjects showed less DA release than healthy controls in response to monetary reward (Martin-Soelch and Drevets, unpublished data).

\section{Cholinergic system}

The cholinergic system is also implicated in the pathophysiology of mood disorders, with evidence indicating that the muscarinic cholinergic system is overactive or 
hyper-responsive in depression. Janowsky et al. (1994) reported that increasing cholinergic activity using the acetylcholine-esterase inhibitor physostigmine resulted in the rapid induction of depressive symptoms in currently manic bipolar subjects, and in a worsening of symptoms in unipolar depressed patients. In addition, depressed individuals express exaggerated polysomnographic, neuroendocrine and pupillary responses to cholinergic agonists or muscarinic receptor agonists relative to healthy controls (Dilsaver 1986; Janowsky et al. 1985; Janowsky and Overstreet 1995; Rubin et al. 1999; Riemann et al. 1994), and aspects of sleep abnormalities observed in depression, including decreased REM latency and increased REM density (Gillin et al. 1979), are thought to reflect hypersensitivity of muscarinic cholinergic receptors. Taken together, these data contribute to the hypothesis that a hyper-responsive cholinergic system may contribute to mood symptoms associated with mood disorders (Janowsky et al. 1994).

The preclinical literature also implicates the muscarinic receptor system in mediating the cholinergic effects on emotional behavior. In a line of rats genetically bred for increased sensitivity of muscarinic receptors, the use of cholinergic agonists results in the enhancement of the behavioral analogs of depression, while the use of antimuscarinic drugs results in the improvement in these behaviors (Overstreet 1993). Consistently, the muscarinic cholinergic receptor antagonist, scopolamine, exerts rapid and robust antidepressant effects in depressed MDD and BD patients (Furey and Drevets 2006).

Several studies more specifically implicate the $\mathrm{M}_{2}$ receptor $\left(\mathrm{M}_{2} \mathrm{R}\right)$ in mood-regulation and depression. Multiple $\mathrm{M}_{2} \mathrm{R}$ gene polymorphisms were associated with increased risk for developing MDE (Comings et al. 2002; Wang et al. 2004). The administration of the $M_{2} R$ antagonist procaine elicits emotional responses in humans ranging from sadness, fear and severe anxiety, to euphoria, and results in increased physiological activity of the cingulate cortex (Ketter et al. 1996; Benson et al. 2004), a region densely innervated by cholinergic projections. Finally, decreased $\mathrm{M}_{2} \mathrm{R}$ binding has been reported in the cingulate cortex in bipolar depressives (Cannon et al. 2006a), using PET-neuroreceptor imaging (Fig. 4).

Cholinergic system dysfunction also may contribute to the subjective sense of impaired concentration and memory, as well as the objective findings of attentional biases in depression. Cholinergic neuromodulation influences multiple cognitive processes, such that cholinergic enhancement generally improves performance on memory and attention tasks (Bartus et al. 1981; Peterson and Gibson 1983) while blocking cholinergic activity impairs
Fig. 4 Reduced muscarinic type 2 (M2) receptor binding in the cingulate cortex in depressed subjects with bipolar disorder relative to healthy controls. The statistical parametric map shows voxel $t$ values corresponding to areas where the uptake of $\left[{ }^{18} \mathrm{~F}\right] \mathrm{FP}-$ TZTP, a PET radioligand which selectively binds $\mathrm{M} 2$ receptors, was significantly reduced (at $P<0.005)$ in bipolar depressives relative to healthy controls. The areas of maximal difference between groups were located in the anterior cingulate cortex. Reproduced from Cannon et al. (2006a)

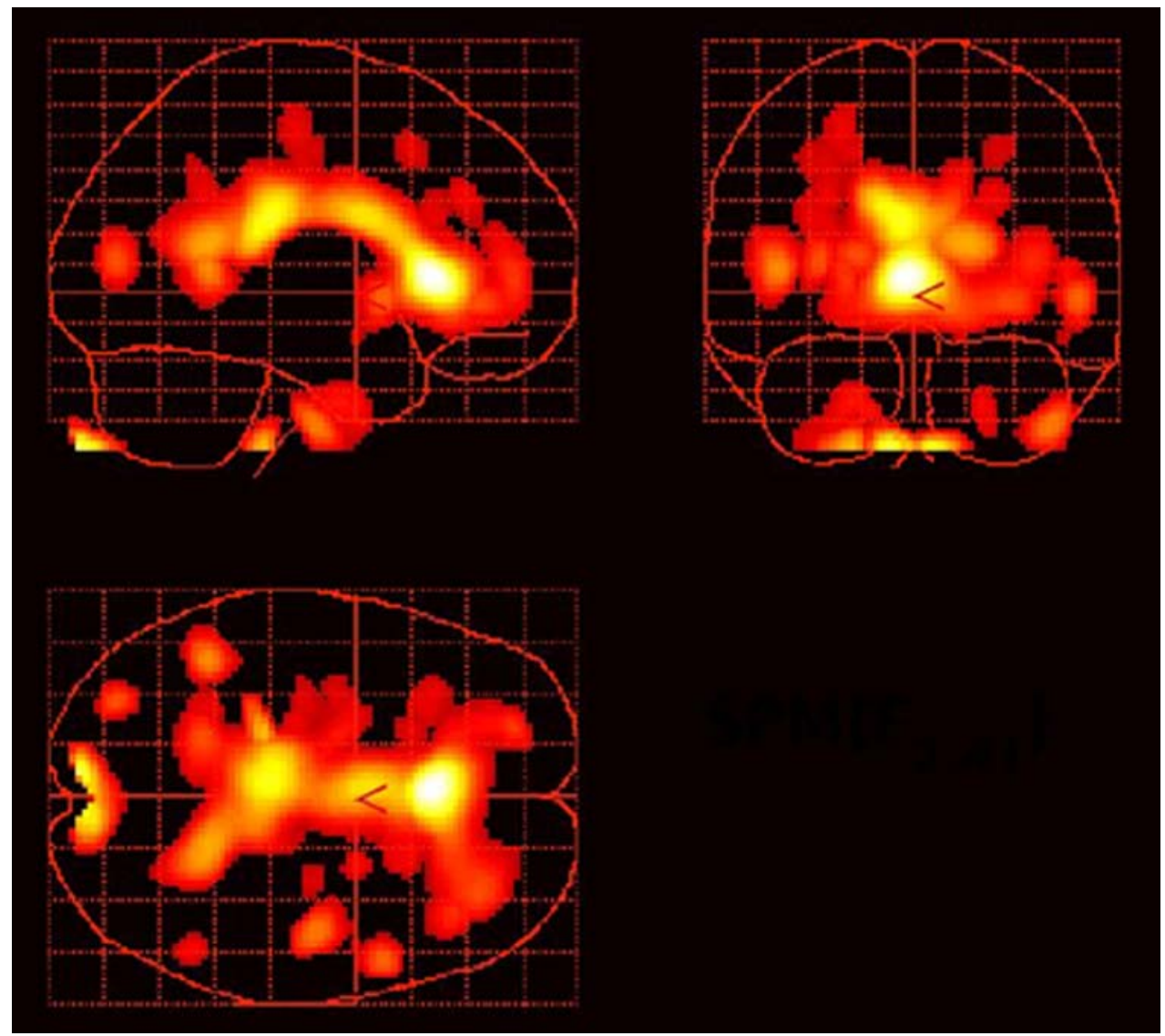


performance (Rusted and Warburton 1988; Sitaram et al. 1978). Acetylcholine is thought to act on neural processing through signal-to-noise $(\mathrm{S} / \mathrm{N})$ mechanisms (Murphy and Sillito 1991; Sato et al. 1987), and consistently researchers have demonstrated that boosting cholinergic activity increases the selectivity of neural response to target sensory stimuli (Furey et al. 2000; Sillito and Kemp 1983; Furey et al. 2007). In this way, the cholinergic influence on $\mathrm{S} / \mathrm{N}$ may represent the neural mechanism that underlies the cholinergic influence on attention. Moreover, acetylcholine modulates emotional processing, both in animals (McGaugh 2004; Power and McGaugh 2002) and in humans (Bentley et al. 2003), and similarly may utilize $\mathrm{S} / \mathrm{N}$ modulation for differential representations of emotional information.

Excessive cortical cholinergic activity in experimental animals results in "hyperattentive impairments" (Sarter et al. 2005), where over activity of the cholinergic system reduces the signal detection threshold and leads to over processing of stimuli. Given the central role of ACh in emotional and sensory processing, the over-activity of the cholinergic system in mood disorders conceivably could alter $\mathrm{S} / \mathrm{N}$ processing to produce an over-representation of emotionally laden information, creating the emotional processing bias and correlated cognitive deficits (see below).

\section{Autonomic nervous system function in mood disorders}

Relative to nondepressed controls matched for cardiac disease, depressed patients show a two to fourfold increase in sudden death and a sevenfold increase in ventricular arrhythmia (Carney et al. 2005). This excess risk of cardiac events in MDD is hypothesized to result partly from elevated noradrenergic and sympathetic autonomic function, coupled with reduced parasympathetic tone on the heart rate (HR) (Carney et al. 2005).

Alterations of cognitive and emotional processing in mood disorders

Cognitive and neuropsychological impairments are characteristics of MDE, and are included in the diagnostic criteria for MDD as "an impaired ability to think or concentrate" (APA 1994). Nonetheless, studies designed to characterize cognitive symptoms in patients with mood disorders have produced discrepant results. Some studies have reported wide-ranging deficits that include impairments in early information processing, attention, memory, and executive functions (Ottowitz et al. 2002; Tavares et al. 2003), while other studies failed to identify such deficits (Channon et al. 1993; Grant et al. 2001; Purcell et al. 1997). Several factors likely contribute to the discrepancies in the literature, including heterogeneous patient groups, medication status, and differences in cognitive task paradigms that are presumed to assess the same cognitive domain. Despite these discrepancies, a sufficient amount of evidence points consistently to the presence of cognitive impairment in MDD and BD. Moreover, the existence of residual cognitive deficits in remitted patient groups demonstrates that some cognitive features occur independently of mood state (Clark et al. 2002; Tham et al. 1997).

\section{Early information processing}

Impairments in early information processing are evident in patients with mood disorders. Inspection time, which is measured as the minimum stimulus presentation time necessary for near perfect performance on a two-choice visual discrimination task, assesses the speed of early information processing independent of motor speed or cognitive strategy. Inspection time was reportedly longer in unmedicated MDD patients than in medicated MDD or in healthy controls (Tsourtos et al. 2002). In a visual backward masking (VBM) task, where a stimulus is shown briefly and then "masked" or covered in space using a noninformative stimulus, medicated BD subjects had deficits in the identification of masked stimuli, consistent with an impairment early in the information processing pathway (Fleming and Green 1995).

\section{Emotional processing bias}

A consistently reported finding in mood disorders is a mood-congruent processing bias, which is defined as a tendency to bias stimulus processing towards negative information as compared to positive or neutral information (Elliott et al. 2000; Murphy et al. 1999; Murray et al. 1999). In memory studies, currently depressed patients have enhanced recall for negatively toned material as compared to positively toned information (Bradley et al. 1995; Murray et al. 1999). In the context of attention paradigms, depression-related negative words produce more interference on emotional stroop tasks than do happy or neutral words (Broomfield et al. 2006; Gallardo Perez et al. 1999). In an affective attention shifting task (i.e., affective go/no-go), medicated (Murphy et al. 1999) and unmedicated (Erickson et al. 2005) depressed subjects are faster when responding to the presentation of sad word as compared to happy word targets, a finding that is consistent with the idea that sad words are processed more readily. In a face dot-probe task designed to assess the allocation of attention between a face with a neutral expression and a face with an emotional expression, individuals with MDD consistently attend preferentially to faces with sad 
expressions (Gotlib et al. 2004a, b). Finally, medicated depressed patients are more negative in their interpretation of ambiguous words (Mogg et al. 2006) and ambiguous situations (Nunn et al. 1997) than are healthy participants. Together, these findings suggest that a bias in stimulus processing exists in patients with mood disorders that may produce a preferential representation of negatively toned information.

Functional neuroimaging studies have been used to assess the relation between processing biases and functional brain response in patients with mood disorders. Results are consistent with behavioral findings, showing altered neurophysiological responses in brain regions that process emotional information (detailed above) during tasks that utilize emotional stimuli. The amygdala shows elevated levels of activity in MDD during exposure to sad faces (Drevets et al. 2001), a finding that has been replicated (Fu et al. 2004). Similarly, increased activity in amygdala was observed during presentation of masked fearful (Sheline et al. 2001) and masked sad faces (Fu et al. 2004) in MDD patients versus healthy controls, and higher activity was seen in lateral orbital cortex following negative emotional stimuli in the affective go/no-go task (Elliott et al. 2002). Similar increases in amygdala activity were observed in response to sad faces in remitted subjects with MDD (Neumeister et al. 2006a), suggesting that this abnormality is trait-like in an MDD subgroup. In another study, healthy volunteers showed a linear increase in activity bilaterally in fusiform visual cortex and ventral striatum as the intensity of a happy facial expression was increased, while MDD patents showed a similar pattern of increase in neural activity as the intensity of a sad expression was increased, but the response pattern in the patient group also extended into hippocampus and amygdala (Surguladze et al. 2005). This literature suggests that neural responses within the neural circuits underlying emotional processing are altered, and that these altered responses may represent the neurophysiological correlates to the emotional processing bias observed in mood disorders.

\section{Attention, memory and learning}

Subjective impairments of concentration and attention are among the most commonly reported symptoms and sources of functional impairment associated with MDE. Although disagreement remains, standard measures of attention and memory that depend on traditional neuropsychological test batteries have failed to identify clear, consistent patterns of deficits in MDD and BD (Elliott et al. 1996; Grant et al. 2001; Purcell et al. 1997; Ravnkilde et al. 2002), and this likely is due partially to the lack of tasks designed specifically for this clinical population. Selective attention (without shifting set) and working memory (Landro et al. 2001; Rose and Ebmeier 2006; Stordal et al. 2004) have been found to be impaired in depression, but these findings have not been found consistently (Purcell et al. 1997), and the results are complicated further by the fact that most patients were medicated during study participation. Deficits in verbal memory have been identified in currently depressed subjects and in unaffected twins and non-twin siblings of BD subjects (Gourovitch et al. 1999; Keri et al. 2001; MacQueen et al. 2002), raising the possibility that impaired verbal memory may constitute an endophenotype for BD. Impairments of spatial recognition memory and delayed matching to sample tasks also have been reported in medicated subjects with MDD and BD (reviewed in Taylor Tavares et al. 2007), but such impairments generally have not been reported in unmedicated samples with MDD or BD (Grant et al. 2001; Purcell et al. 1997).

\section{Implications for neurocircuitry models of depression}

The neuropathological, neurophysiological and neurochemical abnormalities extant within the extended visceromotor network may impair this network's modulation of endocrine, autonomic, neurotransmitter, emotional and behavioral responses to aversive and reward-related stimuli or contexts (Ongür et al. 2003), potentially accounting for the disturbances within these domains in mood disorders (Fig. 5). The abnormally increased CBF and metabolism in the orbital cortex, VLPFC, sgACC, pgACC, amygdala, ventral striatum, and medial thalamus evident in depression (Fig. 3) implicate a limbic-thalamocortical circuit involving the amygdala, the mediodorsal nucleus of the thalamus (MD) and the MPFC, and a limbicstriatal-pallidal-thalamic circuit involving related parts of the striatum and ventral pallidum along with the components of the other circuit (Drevets et al. 1992). The first of these circuits can be conceptualized as an excitatory triangular circuit (Fig. 5) whereby the BLA and the MPFC are interconnected by excitatory (especially glutamatergic) projections with each other and with the MD (Amaral and Price 1984; Amaral and Insausti 1992; Bacon et al. 1996; Kuroda and Price 1991; Jackson and Moghaddam 2001), so increased glucose metabolism in these structures would presumably reflect increased synaptic transmission through the limbic-thalamo-cortical circuit. The limbic-striatalpallidal-thalamic circuit constitutes a disinhibitory side loop between the amygdala or PFC and the MD. The amygdala and the PFC send excitatory projections to overlapping parts of the ventromedial striatum (Russchen et al. 1985). This part of the striatum sends an inhibitory projection to the ventral pallidum (Graybiel 1990) which in turn sends GABA-ergic, inhibitory fibers to the MD 


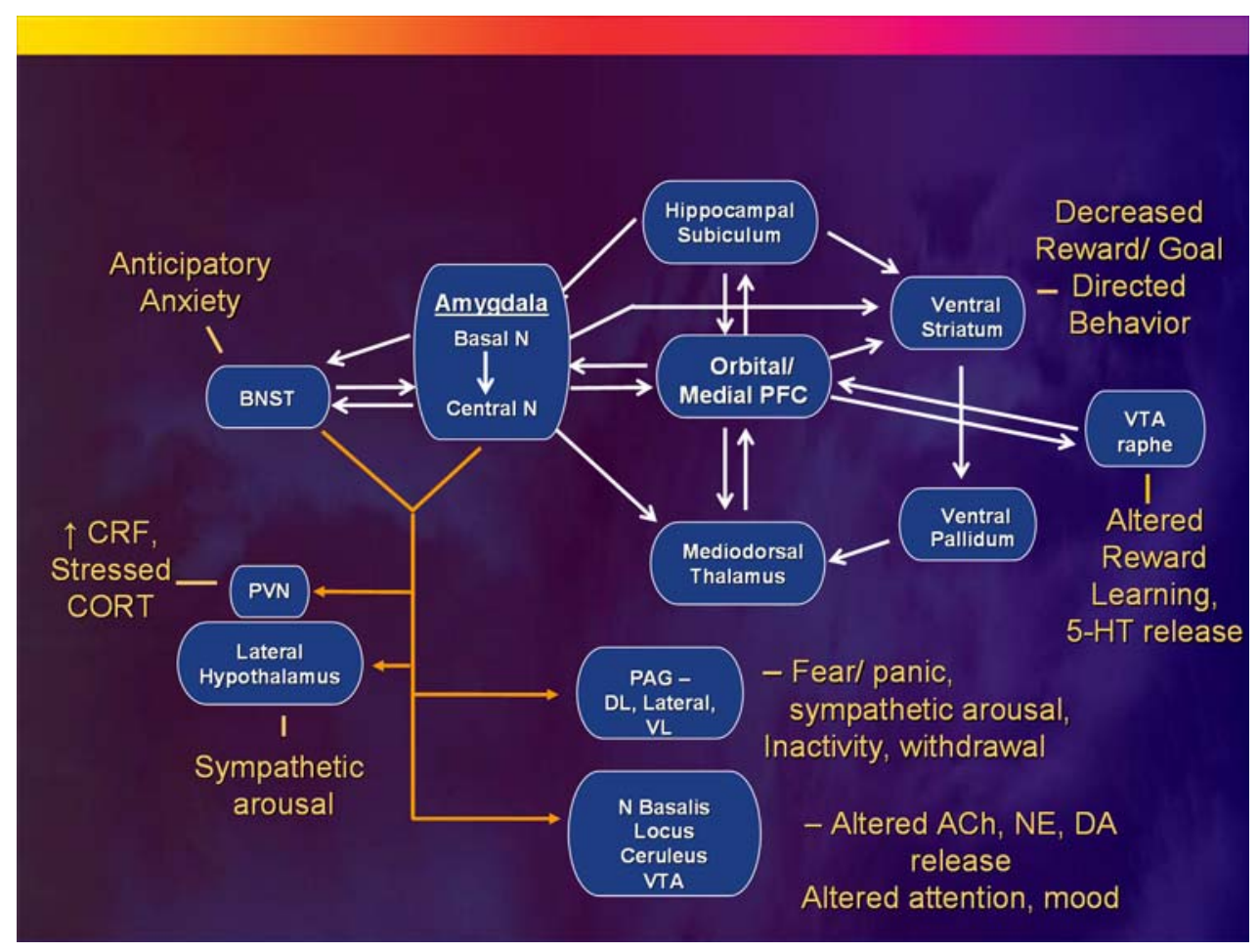

Fig. 5 Anatomical circuits involving the medial PFC (MPFC) and amygdala reviewed within the context of a model in which MPFC dysfunction results in disinhibition of limbic transmission through the amygdala, yielding the emotional, cognitive, endocrine, autonomic and neurochemical manifestations of depression. The basolateral amygdala sends efferent projections to the central nucleus of the amygdala $(A C e)$ and the bed nucleus of the stria terminalis (BNST). The efferent projections from these structures to the hypothalamus, periaqueductal gray $(P A G)$, nucleus basalis, locus ceruleus, raphe and other diencencephalic and brainstem nuclei then organize the neuroendocrine, neurotransmitter, autonomic, and behavioral responses to stressors and emotional stimuli (Davis and Shi 1999; LeDoux 2003). The MPFC shares reciprocal projections with all of these structures (although only the connections with the amygdala are

(Kuroda and Price 1991). Because the pallidal neurons have relatively high spontaneous firing rates (DeLong 1972), activity in the PFC or amygdala that activates the striatum and in turn inhibits the ventral pallidum may release the MD from the inhibitory pallidal influence, potentially disinhibiting transmission through the limbicthalamo-cortical circuitry. Notably, repeated stress results in hyperexcitability states in the BLA in rodents, although whether the mechanisms underlying these changes involve changes in afferent modulation of the amygdala or alterations in synaptic plasticity have not been established (Shekhar et al. 2005; Vyas et al. 2006).

The BLA sends anatomical projections to the central nucleus of the amygdala (ACe) and the BNST, and projections from these structures to the hypothalamus, PAG, nucleus basalis, locus ceruleus, raphe and other diencencephalic and brainstem nuclei play major roles in organizing the neuroendocrine, neurotransmitter, autonomic, illustrated) which function to modulate each component of emotional expression (Ongür et al. 2003). Impaired MPFC function thus may disinhibit or dysregulate limbic outflow through the ACe and BNST. Solid white lines indicate some of the major anatomical connections between structures, with closed arrowheads indicating the direction of projecting axons. Solid yellow lines show efferent pathways of the ACe and BNST, which generally are monosynaptic, but in some cases are bisynaptic connections (e.g., Herman and Cullinan 1997). Other abbreviations: 5-HT serotonin, $A C h$ acetylcholine, $D A$ dopamine, $D L$ dorsolateral column of PAG; $N$ nucleus, $N E$ norepinephrine, NTS nucleus tractus solitarius, $P V N$ paraventricular $\mathrm{N}$ of the hypothalamus, $V L$ ventrolateral column of PAG, VTA ventral tegmental area. Reproduced from Drevets (2007)

and behavioral responses to stressors and emotional stimuli (Davis and Shi 1999; LeDoux 2003). The MPFC sends overlapping projections to each of these structures as well as to the amygdala which function to modulate each component of emotional expression (Ongür et al. 2003). The neuropathological changes evident in the MPFC in primary and some secondary mood disorders thus may impair the modulatory role of the MPFC over emotional expression, disinhibiting or dysregulating limbic responses to stressors and emotional stimuli.

Reciprocal functional relationships between the cortical (e.g., MPFC) and limbic (e.g., amygdala) structures that modulate or mediate emotional expression have been demonstrated by electrophysiological and lesion analysis studies in experimental animals. In rats stimulation of projections from the amygdala to the mPFC inhibits neuronal ensemble activity in the $\mathrm{mPFC}$, and stimulation of projections from the mPFC to the amygdala excites 
intra-amygdaloid GABA-ergic cells that inhibit neuronal activity in the ACe (Likhtik et al. 2005; Perez-Jaranay and Vives 1991). Moreover, rats exposed to fear-conditioned stimuli show reduced mPFC neuronal firing activity, and the magnitude of this decrement correlates inversely with the corresponding increase in amygdala neuron activity and fear behavior (Garcia et al. 1999). Conversely, lesions of the right or bilateral mPFC enhance behavioral, sympathetic, and endocrine responses to stressors or fearconditioned stimuli in rats (Morgan and LeDoux 1995; Sullivan and Gratton 1999).

Reciprocal relationships between the effects of MPFC and amygdala function on emotional behavior also are evident in humans. In MDD depression severity correlates positively with amygdala and sgACC activity, but negatively with activity in the left VLPFC/lateral orbital cortex (Drevets et al. 2004). Lesions of the left orbital cortex increase the risk for developing depression (MacFall et al. 2001), whereas electrical stimulation of the amygdala can produce fear, anxiety, dysphoria, sympathetic autonomic arousal, social withdrawal and cortisol release in humans and/or nonhuman primates (reviewed in Drevets 2001). Drugs and deep brain stimulation that exerts antidepressant effects in MDD show a common effect of reducing physiological activity in the amygdala and/or sgACC, despite having diverse primary actions in the brain (Drevets et al. 2002a; Mayberg et al. 2005; Van Laere et al. 2006). In contrast, a preliminary study found that interpersonal psychotherapy, which also can reduce depressive symptoms in MDD, enhances activity in the VLPFC/anterior insula (Brody et al. 2001a). Finally, higher activity in the pgACC holds positive prognostic significance in MDD, as depressives who improve during antidepressant treatment show higher pgACC metabolism and electrophysiological activity than treatment-nonresponsive cases and healthy controls (Mayberg et al. 1997; Pizzagalli et al. 2001). Taken together, these data suggest that during depressive episodes the increased activity seen within some MPFC areas reflects a compensatory response which modulates depressive symptoms, and impaired function of these regions (possibly due to the neuropathological changes described above) results in more severe and treatmentrefractory illness.

An impairment of MPFC function that disinhibits amygdala activity also may contribute to the neuroendocrine, autonomic, neurotransmitter, attention and rewardseeking abnormalities associated with MDE (Fig. 5). The amygdala mediates the stressed component of glucocorticoid hormone secretion by disinhibiting CRF release from the hypothalamic paraventricular nucleus (Herman and Cullinan 1997). Conversely, the glucocorticoid response to stress is inhibited by stimulation of glucocorticoid receptor (GR) concentrations in the ventral ACC, such that lesioning this cortex in rats increases ACTH and CORT secretion during stress (Diorio et al. 1993). Excessive amygdala activity combined with reduced ventral ACC gray matter thus conceivably may contribute to the excessive cortisol response to stress seen in depressed humans (Drevets et al. 2002b; McEwen and Magarinos 2001; Gold et al. 2002).

The autonomic imbalance associated with depression also could reflect MPFC dysfunction coupled with excessive amygdala activity. Amygdala stimulation of the locus ceruleus, lateral hypothalamus and PAG increases sympathetic autonomic arousal in rodents (Fig. 5) (LeDoux 2003; Gold and Chrousos 2002). In contrast the parasympathetic tone on the heart-rate is partly regulated by projections from the infralimbic cortex (which putatively forms the posterior segment of the human sgACC) to the nucleus tractus solitarius of the vagus nerve, and lesions of this cortex reduce the parasympathetic tone on the heart in rats (Frysztak and Neafsey 1994). The effects of increased amygdala activity and reduced infralimbic cortex function conceivably could account for the increased ratio of sympathetic-to-parasympathetic tone on the heart rate seen in depression (Carney et al. 2005).

Dysfunction of the MPFC coupled with amygdala hyperactivity also may contribute to the anhedonia, amotivation and inattention manifest in depression. The ACC receives extensive dopaminergic innervation from the VTA, and sends projections to the VTA that regulate phasic DA release. In rats, stimulation of these ventral ACC areas elicits burst firing patterns in the VTA-DA neurons, while inactivation of the ventral ACC converts burst firing patterns to pacemaker-like firing activity (Drevets et al. 1998; Murase et al. 1993; Taber and Fibiger 1993; Gariano and Groves 1988). The burst firing patterns increase DA release in the accumbens, which appears to encode information regarding reward prediction in monkeys (Schultz et al. 1997). If the neuropathological changes extant within the ventral ACC in mood disorders interfere with its drive on VTA-DA neuronal burst firing activity they may impair reward perception, conceivably seen as a loss of the pleasure and behavioral reinforcement derived from normally rewarding activities.

In addition, the cognitive and behavioral response patterns supporting goal- or reward-directed activity are thought to depend upon PFC inputs to the ventral striatum, which are maintained or "gated" by projections from the hippocampal subiculum to the ventral striatum (Goto and Grace 2005). Stimulation of projections from the amygdala to the ventral striatum interrupts the maintenance of these cortically driven response patterns, providing an adaptive, limbic override that interrupts goal-directed thought or behavior in response to unexpected threats or novelty. Nevertheless, in MDE the excessive amygdala activity 
conceivably could interfere with cognitive performance and goal directed behavior to an extent that is maladaptive.

Antidepressant treatment effects

Considering the effects of antidepressant treatments on circuitry-based models may elucidate common neurophysiological mechanisms that underlie their therapeutic benefits, despite the diversity of their primary actions in the brain. For example, somatic antidepressant therapies of various types modulate the activity in the amygdala, potentially reducing the efferent transmission from the central nucleus of the amygdala hypothesized to mediate depressive symptoms in the model shown in Fig. 5. Moreover, neurophysiological activity in the amygdala decreases in rats, monkeys and/or humans during administration of treatments that show antidepressant efficacy, including drugs, vagal nerve stimulation or deep brain stimulation of the anterior capsule (Drevets et al. 2002a; Sheline et al. 2001; Fu et al. 2004; Van Laere et al. 2006; Gerber et al. 1983; Henry et al. 1998). Notably in rats (Horovitz 1966) observed that direct injection of antidepressant drugs (AD) into and specific lesions of the central nucleus of the amygdala produced identical effects in animal models used to predict AD efficacy. In addition, metabolism and flow decrease in depressed humans in the sgACC/ventromedial PFC in response to chronic treatment with antidepressant drugs, vagus nerve stimulation or deep brain stimulation of the sgACC or anterior capsule (Mayberg et al. 2005; Drevets et al. 2002a; Van Laere et al. 2006; Mayberg et al. 1999; Nahas et al. 2007; Conway et al. 2006).

In considering broader networks, activity in the limbicthalamo-cortical circuitry decreases during effective treatment (Drevets et al. 2002a; Drevets et al. 2004). The cortical areas implicated include the orbital cortex, ventrolateral PFC, and/or anterior insula, where many studies report that flow or metabolism decrease during treatment with antidepressant drugs or electroconvulsive therapy (e.g., Brody et al. 2001b; Drevets 1992; Mayberg et al. 1999; Nobler et al. 1994). These areas show complex relationships between depression severity and physiological activity. While CBF and metabolism increase in these areas in the depressed relative to the remitted phases of MDD, the magnitude of these measures correlates inversely with ratings of depression severity (Drevets et al. 1992). An inverse relationship between posterior orbital cortex activity and the intensity of emotional experience also is evident during anxiety provocation in subjects with obsessive-complusive disorder and induced sadness in healthy humans (Rauch et al. 1994; Schneider et al. 1995). These data appear consistent with electrophysiological data showing that parts of the orbital cortex participate in modulating behavioral and visceral responses associated with defensive, fear, and reward-directed behavior (Timms 1977; Rolls 1995), and that cerebrovascular lesions of the frontal lobe (Starkstein and Robinson 1989) or more specifically the orbitofrontal cortex (MacFall et al. 2001) increase the risk for developing major depression. Activation of the orbital cortex during depression thus may reflect compensatory attempts to modulate emotional expression or interrupt unreinforced aversive thought and emotion. If so, then reducing $\mathrm{CBF}$ and metabolism in the orbital cortex and ventrolateral PFC during antidepressant drug treatment and electroconvulsive therapy may not constitute a primary mechanism for ameliorating depressive symptoms. Instead, direct inhibition of pathological limbic activity in areas such as the amygdala and sgACC may be more essential to correcting the pathophysiology associated with mediating depressive symptoms, and the reduction in orbital cortex/VLPFC activity may reflect a secondary relaxation of these areas, once they are no longer recruited to modulate pathological limbic activity.

Finally, preliminary reports observe that chronic SSRI treatment or deep brain stimulation of the anterior capsule additionally reduces the abnormally elevated metabolism in the accumbens area in depression (Drevets et al. 2006) or in depression associated with obsessive-complusive disorder (Van Laere et al. 2006), and that deep brain stimulation applied via electrodes situated in the accumbens area/ventral internal capsule reportedly improves depressive symptoms in treatment-refractory depression (Schlaepfer et al. 2008). Taken together, these data suggest the importance of modulating activity within the limbic-striatalpallidal-thalamic circuitry in the treatment of depression.

Cognitive-behavioral strategies for managing depressive symptoms may instead rely upon enhancing the function of PFC systems that modulate limbic activity, thereby enhancing the normal role of cortico-limbic circuits in modulating emotional expression and experience (Siegle et al. 2006). For example, interpersonal psychotherapy can reduce depressive symptoms in MDD, and has been shown to enhance activity in the VLPFC/anterior insula (Brody et al. 2001a).

\section{Summary}

Convergent results from studies conducted using neuroimaging, lesion analysis and post mortem techniques support models in which the signs and symptoms of depression emanate from dysfunction within an extended visceromotor network, which interferes with this system's modulation of emotional behavior. We have proposed more specifically that the effects of impaired function in and between the MPFC and related limbic structures can account for the 
disturbances of emotional processing, cognitive performance, neurotransmission, autonomic regulation and neuroendocrine responses that are associated with mood disorders. Somatic antidepressant therapies may compensate for this dysfunction by modulating the pathological limbic activity which putatively mediates depressive symptoms (Drevets et al. 2002a) and the expression of neurotrophic/ neuroprotective factors that preserve the function of the MPFC (Manji et al. 2001). Cognitive-behavioral strategies for managing depressive symptoms may instead rely upon enhancing the function of these MPFC systems, thereby enhancing the normal role of cortico-limbic circuits in modulating emotional processing and experience.

Open Access This article is distributed under the terms of the Creative Commons Attribution Noncommercial License which permits any noncommercial use, distribution, and reproduction in any medium, provided the original author(s) and source are credited.

\section{References}

Alonso G (2000) Prolonged corticosterone treatment of adult rats inhibits the proliferation of oligodendrocyte progenitors present throughout white and gray matter regions of the brain. Glia 31:219-231. doi:10.1002/1098-1136(200009)31:3<219::AIDGLIA30 $>3.0 . C O ; 2-R$

Amaral DG, Insausti R (1992) Retrograde transport of D-[3H]aspartate injected into the monkey amygdaloid complex. Exp Brain Res 88:375-388. doi:10.1007/BF02259113

Amaral DG, Price JL (1984) Amygdalo-cortical projections in the monkey (Macaca fascicularis). J Comp Neurol 230:465-496. doi:10.1002/cne. 902300402

APA (1994) Diagnostic and statistical manual of mental disorders (DSM-IV). APA Press, Washington, DC

Aston C, Jiang L, Sokolov BP (2005) Transcriptional profiling reveals evidence for signaling and oligodendroglial abnormalities in the temporal cortex from patients with major depressive disorder. Mol Psychiatry 10:309-322. doi:10.1038/sj.mp.4001565

Bacon SJ, Headlam AJ, Gabbott PL, Smith AD (1996) Amygdala input to medial prefrontal cortex (mPFC) in the rat: a light and electron microscope study. Brain Res 720:211-219. doi:10.1016/ 0006-8993(96)00155-2

Banasr M, Duman RS (2007) Regulation of neurogenesis and gliogenesis by stress and antidepressant treatment. CNS Neurol Disord Drug Targets 6:311-320. doi:10.2174/187152707783220929

Barton DA, Esler MD, Dawood T, Lambert EA, Haikerwal D, Brenchley C et al (2008) Elevated brain serotonin turnover in patients with depression: effect of genotype and therapy. Arch Gen Psychiatry 65:38-46. doi:10.1001/archgenpsychiatry. 2007.11

Bartus RT, Dean RL III, Sherman KA, Friedman E, Beer B (1981) Profound effects of combining choline and piracetam on memory enhancement and cholinergic function in aged rats. Neurobiol Aging 2:105-111. doi:10.1016/0197-4580(81)90007-5

Baumann BDP, Krell D, Diekmann S, Leschinger A, Stauch R, Wurthman C, Bernstein H-G, Bogerts B (1999) Reduced volume of limbic system-affiliated basal ganglia in mood disorders: preliminary data from a post mortem study. J Neuropsychiatry Clin Neurosci 11:71-78
Benes FM, Vincent SL, Todtenkopf M (2001) The density of pyramidal and nonpyramidal neurons in anterior cingulate cortex of schizophrenic and bipolar subjects. Biol Psychiatry 50:395406. doi:10.1016/S0006-3223(01)01084-8

Benson BE, Carson RE, Kiesewetter DO, Herscovitch P, Eckelman WC, Post RM et al (2004) A potential cholinergic mechanism of procaine's limbic activation. Neuropsychopharmacology 29:1239-1250. doi:10.1038/sj.npp.1300404

Bentley P, Vuilleumier P, Thiel CM, Driver J, Dolan RJ (2003) Effects of attention and emotion on repetition priming and their modulation by cholinergic enhancement. J Neurophysiol 90:1171-1181. doi:10.1152/jn.00776.2002

Botteron KN, Raichle ME, Drevets WC, Heath AC, Todd RD (2002) Volumetric reduction in left subgenual prefrontal cortex in early onset depression. Biol Psychiatry 51:342-344. doi:10.1016/ S0006-3223(01)01280-X

Bowen DM, Najlerahim A, Procter AW, Francis PT, Murphy E (1989) Circumscribed changes of the cerebral cortex in neuropsychiatric disorders of later life. Proc Natl Acad Sci USA 86:9504-9508. doi:10.1073/pnas.86.23.9504

Bowley MP, Drevets WC, Ongür D, Price JL (2002) Low glial numbers in the amygdala in major depressive disorder. Biol Psychiatry 52:404-412. doi:10.1016/S0006-3223(02)01404-X

Bradley BP, Mogg K, Williams R (1995) Implicit and explicit memory for emotion-congruent information in clinical depression and anxiety. Behav Res Ther 33:755-770. doi:10.1016/ 0005-7967(95)00029-W

Brambilla P, Nicoletti M, Sassi RB, Mallinger AG, Frank E, Keshavan MS et al (2004) Corpus callosum signal intensity in patients with bipolar and unipolar disorder. J Neurol Neurosurg Psychiatry 75:221-225

Brody AL, Saxena S, Stoessel P, Gillies LA, Fairbanks LA, Alborzian $S$ et al (2001a) Regional brain metabolic changes in patients with major depression treated with either paroxetine or interpersonal therapy: preliminary findings. Arch Gen Psychiatry 58:631-640. doi:10.1001/archpsyc.58.7.631

Brody AL, Saxena S, Stoessel P, Gillies LA, Fairbanks LA, Alborzian $S$ et al (2001b) Regional brain metabolic changes in patients with major depression treated with either paroxetine or interpersonal therapy: preliminary findings. Arch Gen Psychiatry 58:631-640. doi:10.1001/archpsyc.58.7.631 see comments

Broomfield NM, Davies R, Macmahon K, Ali F, Cross SM (2006) Further evidence of attention bias for negative information in late life depression. Int J Geriatr Psychiatry 22(3):175-180

Cannon DM, Carson RE, Nugent AC, Eckelman WC, Kiesewetter DO, Williams J et al (2006a) Reduced muscarinic type 2 receptor binding in subjects with bipolar disorder. Arch Gen Psychiatry 63:741-747. doi:10.1001/archpsyc.63.7.741

Cannon DM, Ichise M, Fromm SJ, Nugent AC, Rollis D, Gandhi SK et al (2006b) Serotonin transporter binding in bipolar disorder assessed using [11C]DASB and positron emission tomography. Biol Psychiatry 60:207-217. doi:10.1016/j.biopsych.2006. 05.005

Cannon DM, Ichise M, Rollis D, Klaver JM, Gandhi SK, Charney DS et al (2007) Elevated serotonin transporter binding in major depressive disorder assessed using positron emission tomography and [11C]DASB; comparison with bipolar disorder. Biol Psychiatry 62:870-877. doi:10.1016/j.biopsych.2007. 03.016

Carmichael ST, Price JL (1994) Architectonic subdivision of the orbital and medial prefrontal cortex in the macaque monkey. J Comp Neurol 346:366-402. doi:10.1002/cne.903460305

Carmichael ST, Price JL (1995) Limbic connections of the orbital and medial prefrontal cortex in macaque monkeys. J Comp Neurol 363:615-641. doi:10.1002/cne.903630408 
Carney RM, Freedland KE, Veith RC (2005) Depression, the autonomic nervous system, and coronary heart disease. Psychosom Med 67:S29-S33. doi:10.1097/01.psy.0000162254.61556.d5

Carroll BJ, Feinberg M, Greden JF, Tarika J, Albala AA, Haskett RF et al (1981) A specific laboratory test for the diagnosis of melancholia. Standardization, validation, and clinical utility. Arch Gen Psychiatry 38:15-22

Carroll BJ, Cassidy F, Naftolowitz D, Tatham NE, Wilson WH, Iranmanesh A et al (2007) Pathophysiology of hypercortisolism in depression. Acta Psychiatr Scand Suppl 433:90-103. doi: 10.1111/j.1600-0447.2007.00967.x

Caspi A, Sugden K, Moffitt TE, Taylor A, Craig IW, Harrington H et al (2003) Influence of life stress on depression: moderation by a polymorphism in the 5-HTT gene. Science 301:386-389. doi: $10.1126 /$ science. 1083968

Channon S, Baker JE, Robertson MM (1993) Working memory in clinical depression: an experimental study. Psychol Med 23:87-91

Chaput Y, De Montigny C, Blier P (1991) Presynaptic and postsynaptic modifications of the serotonin system by long-term administration of antidepressant treatments. An in vivo electrophysiologic study in the rat. Neuropsychopharmacology 5:219-229

Charney DS, Drevets WC (2002) The neurobiological basis of anxiety disorders. In: Davis K, Charney DS, Coyle J, Nemeroff CB (eds) Psychopharmacology The fifth generation of progress. Williams and Wilkins, New York/Lippencott

Cheng JD, De Vellis J (2000) Oligodendrocytes as glucocorticoids target cells: functional analysis of the glycerol phosphate dehydrogenase gene. J Neurosci Res 59:436-445. doi:10.1002/(SICI)10974547(20000201)59:3<436::AID-JNR19>3.0.CO;2-Z

Clark L, Iversen SD, Goodwin GM (2002) Sustained attention deficit in bipolar disorder. Br J Psychiatry 180:313-319. doi:10.1192/ bjp. 180.4 .313

Comings DE, Wu S, Rostamkhani M, Mcgue M, Iacono WG, Macmurray JP (2002) Association of the muscarinic cholinergic 2 receptor (CHRM2) gene with major depression in women. Am J Med Genet 114:527-529. doi:10.1002/ajmg.10406

Conrad CD, Ledoux JE, Magarinos AM, Mcewen BS (1999) Repeated restraint stress facilitates fear conditioning independently of causing hippocampal CA3 dendritic atrophy. Behav Neurosci 113:902-913. doi:10.1037/0735-7044.113.5.902

Conway CR, Sheline YI, Chibnall JT, George MS, Fletcher JW, Mintun MA (2006) Cerebral blood flow changes during vagus nerve stimulation for depression. Psychiatry Res 146:179-184. doi:10.1016/j.pscychresns.2005.12.007

Coryell W, Nopoulos P, Drevets W, Wilson T, Andreasen NC (2005) Subgenual prefrontal cortex volumes in major depressive disorder and schizophrenia: diagnostic specificity and prognostic implications. Am J Psychiatry 162:1706-1712. doi:10.1176/ appi.ajp.162.9.1706

Cotter D, Mackay D, Landau S, Kerwin R, Everall I (2001a) Reduced glial cell density and neuronal size in the anterior cingulate cortex in major depressive disorder. Arch Gen Psychiatry 58:545-553. doi:10.1001/archpsyc.58.6.545

Cotter DR, Pariante CM, Everall IP (2001b) Glial cell abnormalities in major psychiatric disorders: the evidence and implications. Brain Res Bull 55:585-595. doi:10.1016/S0361-9230(01) 00527-5

Cotter D, Mackay D, Chana G, Beasley C, Landau S, Everall IP (2002) Reduced neuronal size and glial cell density in area 9 of the dorsolateral prefrontal cortex in subjects with major depressive disorder. Cereb Cortex 12:386-394. doi:10.1093/cercor/ 12.4.386

Czeh B, Simon M, Schmelting B, Hiemke C, Fuchs E (2005) Astroglial plasticity in the hippocampus is affected by chronic psychosocial stress and concomitant fluoxetine treatment. Neuropsychopharmacology 31(8):1616-1626
D'Amelio F, Eng LF, Gibbs MA (1990) Glutamine synthetase immunoreactivity is present in oligodendroglia of various regions of the central nervous system. Glia 3:335-341. doi: 10.1002/glia.440030504

Davis M, Shi C (1999) The extended amygdala: are the central nucleus of the amygdala and the bed nucleus of the stria terminalis differentially involved in fear versus anxiety? Ann N Y Acad Sci 877:281291. doi:10.1111/j.1749-6632.1999.tb09273.x

Delong MR (1972) Activity of basal ganglia neurons during movement. Brain Res 40:127-135. doi:10.1016/0006-8993(72) 90118-7

Detera-Wadleigh SD, Mcmahon FJ (2004) Genetic association studies in mood disorders: issues and promise. Int Rev Psychiatry 16:301-310. doi:10.1080/09540260400014377

Dewar D, Underhill SM, Goldberg MP (2003) Oligodendrocytes and ischemic brain injury. J Cereb Blood Flow Metab 23:263-274. doi:10.1097/00004647-200303000-00001

Dilsaver SC (1986) Pathophysiology of "cholinoceptor supersensitivity" in affective disorders. Biol Psychiatry 21:813-829. doi: 10.1016/0006-3223(86)90246-5

Diorio D, Viau V, Meaney MJ (1993) The role of the medial prefrontal cortex (cingulate gyrus) in the regulation of hypothalamic-pituitary-adrenal responses to stress. J Neurosci 13:3839_ 3847

Drevets WC (2001) Neuroimaging and neuropathological studies of depression: implications for the cognitive-emotional features of mood disorders. Curr Opin Neurobiol 11:240-249. doi:10.1016/ S0959-4388(00)00203-8

Drevets WC (2003) Neuroimaging abnormalities in the amygdala in mood disorders. Ann N Y Acad Sci 985:420-444

Drevets WC (2007) Orbitofrontal cortex function and structure in depression. Ann NY Acad Sci 1121:499-527. doi:10.1196/annals. 1401.029

Drevets WC, Price JL (2005) Neuroimaging and neuropathological studies of mood disorders. In: Licinio JWM (ed) Biology of depression: from novel insights to therapeutic strategies. WileyVCH Verlag GmbH \& Co., Weinheim

Drevets and Raichle (1992) Neuroanatomical circuits in depression: Implications for treatment mechanisms. Psychopharmacol Bull 28:261-274

Drevets WC, Savitz J (2008) The subgenual anterior cingulate cortex in mood disorders. CNS Spectr 13(8):663-681

Drevets WC, Todd RD (2005) Depression, mania and related disorders. In: Rubin E, Zorumski C (eds) Adult psychiatry, 2nd edn. Blackwell Publishing, Oxford

Drevets WC, Videen TO, Price JL, Preskorn SH, Carmichael ST, Raichle ME (1992) A functional anatomical study of unipolar depression. J Neurosci 12:3628-3641

Drevets WC, Price JL, Simpson JR Jr, Todd RD, Reich T, Vannier M et al (1997) Subgenual prefrontal cortex abnormalities in mood disorders. Nature 386:824-827. doi:10.1038/386824a0

Drevets WC, Ongür D, Price JL (1998) Neuroimaging abnormalities in the subgenual prefrontal cortex: implications for the pathophysiology of familial mood disorders. Mol Psychiatry 3:220$226190-1$

Drevets WC, Frank E, Price JC, Kupfer DJ, Holt D, Greer PJ et al (1999) PET imaging of serotonin 1A receptor binding in depression. Biol Psychiatry 46:1375-1387. doi:10.1016/S00063223(99)00189-4

Drevets WC, Gautier C, Lowry T, Bogers W, Greer P, Kupfer DJ (2001) Abnormal hemodynamic responses to facially expressed emotion in major depression. Soc Neurosci Abstr 27:785.1

Drevets WC, Bogers W, Raichle ME (2002a) Functional anatomical correlates of antidepressant drug treatment assessed using PET measures of regional glucose metabolism. Eur Neuropsychopharmacol 12:527-544. doi:10.1016/S0924-977X(02)00102-5 
Drevets WC, Price JL, Bardgett ME, Reich T, Todd RD, Raichle ME (2002b) Glucose metabolism in the amygdala in depression: relationship to diagnostic subtype and plasma cortisol levels. Pharmacol Biochem Behav 71:431-447. doi:10.1016/S00913057(01)00687-6

Drevets WC, Gadde K, Krishnan KRR (2004) Neuroimaging studies of depression. In: Charney DS, Nestler EJ, Bunney BS (eds) The neurobiological foundation of mental illness, 2nd edn. Oxford University Press, New York

Drevets WC, Kupfer DJ, Bogers W, Thase M (2006) Glucose metabolism in dorsal versus ventral striatum differentiates major depressive subtypes. Soc Neurosci Abstr 782.8

Drevets WC, Thase ME, Moses-Kolko EL, Price J, Frank E, Kupfer DJ et al (2007) Serotonin-1A receptor imaging in recurrent depression: replication and literature review. Nucl Med Biol 34:865-877. doi:10.1016/j.nucmedbio.2007.06.008

Eastwood SL, Harrison PJ (2000) Hippocampal synaptic pathology in schizophrenia, bipolar disorder and major depression: a study of complexin mRNAs. Mol Psychiatry 5:425-432. doi:10.1038/ sj.mp.4000741

Eastwood SL, Harrison PJ (2001) Synaptic pathology in the anterior cingulate cortex in schizophrenia and mood disorders. A review and a Western blot study of synaptophysin, GAP-43 and the complexins. Brain Res Bull 55:569-578. doi:10.1016/S03619230(01)00530-5

Elliott R, Sahakian BJ, Mckay AP, Herrod JJ, Robbins TW, Paykel ES (1996) Neuropsychological impairments in unipolar depression: the influence of perceived failure on subsequent performance. Psychol Med 26:975-989

Elliott R, Rubinsztein JS, Sahakian BJ, Dolan RJ (2000) Selective attention to emotional stimuli in a verbal go/no-go task: an fMRI study. NeuroReport 11:1739-1744

Elliott R, Rubinsztein JS, Sahakian BJ, Dolan RJ (2002) The neural basis of mood-congruent processing biases in depression. Arch Gen Psychiatry 59:597-604. doi:10.1001/archpsyc.59.7.597

Erickson K, Drevets WC, Clark L, Cannon DM, Bain EE, Zarate CA $\mathrm{Jr}$ et al (2005) Mood-congruent bias in affective go/no-go performance of unmedicated patients with major depressive disorder. Am J Psychiatry 162:2171-2173. doi:10.1176/appi.ajp. 162.11.2171

Fleming K, Green MF (1995) Backward masking performance during and after manic episodes. J Abnorm Psychol 104:63-68. doi: 10.1037/0021-843X.104.1.63

Floyd NS, Price JL, Ferry AT, Keay KA, Bandler R (2000) Orbitomedial prefrontal cortical projections to distinct longitudinal columns of the periaqueductal gray in the rat. J Comp Neurol 422:556-578. doi:10.1002/1096-9861(20000710)422: $4<556::$ AID-CNE6 $>3.0 . \mathrm{CO} ; 2-\mathrm{U}$

Floyd NS, Price JL, Ferry AT, Keay KA, Bandler R (2001) Orbitomedial prefrontal cortical projections to hypothalamus in the rat. J Comp Neurol 432:307-328. doi:10.1002/cne.1105

Flugge G (1995) Dynamics of central nervous 5-HT1A-receptors under psychosocial stress. J Neurosci 15:7132-7140

Folstein MF, Robinson R, Folstein S, Mchugh PR (1985) Depression and neurological disorders. New treatment opportunities for elderly depressed patients. J Affect Disord Suppl 1:S11-S14. doi:10.1016/0165-0327(85)90083-7

Fox MD, Snyder AZ, Vincent JL, Corbetta M, Van Essen DC, Raichle ME (2005) The human brain is intrinsically organized into dynamic, anticorrelated functional networks. Proc Natl Acad Sci USA 102:9673-9678

Frysztak RJ, Neafsey EJ (1994) The effect of medial frontal cortex lesions on cardiovascular conditioned emotional responses in the rat. Brain Res 643:181-193. doi:10.1016/0006-8993(94)90024-8

Fu CH, Williams SC, Cleare AJ, Brammer MJ, Walsh ND, Kim J et al (2004) Attenuation of the neural response to sad faces in major depression by antidepressant treatment: a prospective, eventrelated functional magnetic resonance imaging study. Arch Gen Psychiatry 61:877-889. doi:10.1001/archpsyc.61.9.877

Furey ML, Drevets WC (2006) Antidepressant efficacy of the antimuscarinic drug scopolamine: a randomized, placebocontrolled clinical trial. Arch Gen Psychiatry 63:1121-1129. doi: 10.1001/archpsyc.63.10.1121

Furey ML, Pietrini P, Haxby JV (2000) Cholinergic enhancement and increased selectivity of perceptual processing during working memory. Science 290:2315-2319. doi:10.1126/science.290. 5500.2315

Furey ML, Pietrini P, Haxby JV, Drevets WC (2007) Selective effects of cholinergic modulation on task performance during selective attention. Neuropsychopharmacology 33(4):913-923

Gallardo Perez M, Banos Rivera RM, Belloch Fuster A, Ruiperez Rodriguez MA (1999) Attentional biases and vulnerability to depression. Span J Psychol 2:11-19

Garcia R, Vouimba RM, Baudry M, Thompson RF (1999) The amygdala modulates prefrontal cortex activity relative to conditioned fear. Nature 402:294-296. doi:10.1038/46286

Gariano RF, Groves PM (1988) Burst firing induced in midbrain dopamine neurons by stimulation of the medial prefrontal and anterior cingulate cortices. Brain Res 462:194-198. doi:10.1016/ 0006-8993(88)90606-3

Gerber JC III, Choki J, Brunswick DJ, Reivich M, Frazer A (1983) The effect of antidepressant drugs on regional cerebral glucose utilization in the rat. Brain Res 269:319-325. doi:10.1016/ 0006-8993(83)90142-7

Gillin JC, Sitaram N, Duncan WC (1979) Muscarinic supersensitivity: a possible model for the sleep disturbance of primary depression? Psychiatry Res 1:17-22. doi:10.1016/0165-1781(79) 90023-4

Gold PW, Chrousos GP (2002) Organization of the stress system and its dysregulation in melancholic and atypical depression: high vs low CRH/NE states. Mol Psychiatry 7:254-275. doi:10.1038/ sj.mp. 4001032

Gold PW, Drevets WC, Charney DS (2002) New insights into the role of cortisol and the glucocorticoid receptor in severe depression. Biol Psychiatry 52:381-385. doi:10.1016/S0006-3223(02)01480-4

Gotlib IH, Kasch KL, Traill S, Joormann J, Arnow BA, Johnson SL (2004a) Coherence and specificity of information-processing biases in depression and social phobia. J Abnorm Psychol 113:386-398. doi:10.1037/0021-843X.113.3.386

Gotlib IH, Krasnoperova E, Yue DN, Joormann J (2004b) Attentional biases for negative interpersonal stimuli in clinical depression. J Abnorm Psychol 113:121-135

Goto Y, Grace AA (2005) Dopaminergic modulation of limbic and cortical drive of nucleus accumbens in goal-directed behavior. Nat Neurosci 8:805-812. doi:10.1038/nn1471

Gourovitch ML, Torrey EF, Gold JM, Randolph C, Weinberger DR, Goldberg TE (1999) Neuropsychological performance of monozygotic twins discordant for bipolar disorder. Biol Psychiatry 45:639-646. doi:10.1016/S0006-3223(98)00148-6

Grant MM, Thase ME, Sweeney JA (2001) Cognitive disturbance in outpatient depressed younger adults: evidence of modest impairment. Biol Psychiatry 50:35-43. doi:10.1016/S00063223(00)01072-6

Graybiel AM (1990) Neurotransmitters and neuromodulators in the basal ganglia. Trends Neurosci 13:244-254. doi:10.1016/01662236(90)90104-I

Gross C, Zhuang X, Stark K, Ramboz S, Oosting R, Kirby L et al (2002) Serotonin1A receptor acts during development to establish normal anxiety-like behaviour in the adult. Nature 416:396400. doi:10.1038/416396a

Gusnard DA, Akbudak E, Shulman GL, Raichle ME (2001) Medial prefrontal cortex and self-referential mental activity: relation to a 
default mode of brain function. Proc Natl Acad Sci USA 98:4259-4264

Haddjeri N, Blier P, De Montigny C (1998) Long-term antidepressant treatments result in a tonic activation of forebrain 5-HT1A receptors. J Neurosci 18:10150-10156

Hamidi M, Drevets WC, Price JL (2004) Glial reduction in amygdala in major depressive disorder is due to oligodendrocytes. Biol Psychiatry 55:563-569. doi:10.1016/j.biopsych. 2003.11.006

Hasler G, Van Der Veen JW, Tumonis T, Meyers N, Shen J, Drevets WC (2007) Reduced prefrontal glutamate/glutamine and gamma-aminobutyric acid levels in major depression determined using proton magnetic resonance spectroscopy. Arch Gen Psychiatry 64:193-200. doi:10.1001/archpsyc.64.2.193

Hasler G, Fromm S, Luckenbaugh DA, Carlson PJ, Waldeck T, Geraci $M$ et al (2008) Neural response to catecholamine depletion in unmedicated, remitted subjects with major depressive disorder and healthy subjects. Arch Gen Psychiatry (in press)

Henry TR, Bakay RA, Votaw JR, Pennell PB, Epstein CM, Faber TL et al (1998) Brain blood flow alterations induced by therapeutic vagus nerve stimulation in partial epilepsy: I. Acute effects at high and low levels of stimulation. Epilepsia 39:983-990. doi: 10.1111/j.1528-1157.1998.tb01448.x

Herman JP, Cullinan WE (1997) Neurocircuitry of stress: central control of the hypothalamo-pituitary-adrenocortical axis. Trends Neurosci 20:78-84. doi:10.1016/S0166-2236(96)10069-2

Hirayasu Y, Shenton ME, Salisbury DF, Kwon JS, Wible CG, Fischer IA et al (1999) Subgenual cingulate cortex volume in firstepisode psychosis. Am J Psychiatry 156:1091-1093

Honer WG, Falkai P, Chen C, Arango V, Mann JJ, Dwork AJ (1999) Synaptic and plasticity-associated proteins in anterior frontal cortex in severe mental illness. Neuroscience 91:1247-1255. doi: 10.1016/S0306-4522(98)00679-4

Horovitz Z (1966) The amygdala and depression. In: Garattini S, Dukes M (eds) Antidepressant drugs. Excerpta Medica, Amsterdam

Hsu DT, Price JL (2007) Midline and intralaminar thalamic connections with the orbital and medial prefrontal networks in macaque monkeys. J Comp Neurol 504:89-111. doi:10.1002/ cne. 21440

Husain MM, McDonald WM, Doraiswamy PM et al (1991) A magnetic resonance imaging study of putamen nuclei in major depression. Psychiatry Res 40:95-99

Inoue $\mathrm{T}$, Tsuchiya K, Koyama $\mathrm{T}$ (1994) Regional changes in dopamine and serotonin activation with various intensity of physical and psychological stress in the rat brain. Pharmacol Biochem Behav 49:911-920. doi:10.1016/0091-3057(94) 90243-7

Izquierdo A, Wellman CL, Holmes A (2006) Brief uncontrollable stress causes dendritic retraction in infralimbic cortex and resistance to fear extinction in mice. J Neurosci 26:5733-5738. doi:10.1523/JNEUROSCI.0474-06.2006

Jackson ME, Moghaddam B (2001) Amygdala regulation of nucleus accumbens dopamine output is governed by the prefrontal cortex. J Neurosci 21:676-681

Janowsky DS, Overstreet DH (1995) The role of acetylcholine mechanisms in mood disorders. Raven Press, New York

Janowsky DS, Risch SC, Huey LY, Kennedy B, Ziegler M (1985) Effects of physostigmine on pulse, blood pressure, and serum epinephrine levels. Am J Psychiatry 142:738-740

Janowsky DS, Overstreet DH, Nurnberger JI Jr (1994) Is cholinergic sensitivity a genetic marker for the affective disorders? Am J Med Genet 54:335-344. doi:10.1002/ajmg.1320540412

Johnston-Wilson NL, Sims CD, Hofmann JP, Anderson L, Shore AD, Torrey EF et al (2000) Disease-specific alterations in frontal cortex brain proteins in schizophrenia, bipolar disorder, and major depressive disorder. The Stanley Neuropathology Consortium. Mol Psychiatry 5:142-149. doi:10.1038/sj.mp.4000696

Keri S, Kelemen O, Benedek G, Janka Z (2001) Different trait markers for schizophrenia and bipolar disorder: a neurocognitive approach. Psychol Med 31:915-922. doi:10.1017/S0033291 701004068

Kessler RC, Chiu WT, Demler O, Walters EE (2005) Prevalence, severity, and comorbidity of 12-month DSM-IV disorders in the National Comorbidity Survey Replication. Arch Gen Psychiatry 62:617-627. doi:10.1001/archpsyc.62.6.617

Ketter TA, Andreason PJ, George MS, Lee C, Gill DS, Parekh PI et al (1996) Anterior paralimbic mediation of procaine-induced emotional and psychosensory experiences. Arch Gen Psychiatry 53:59-69

Ketter TA, Kimbrell TA, George MS, Dunn RT, Speer AM, Benson BE et al (2001) Effects of mood and subtype on cerebral glucose metabolism in treatment-resistant bipolar disorder. Biol Psychiatry 49:97-109

Knutson B, Bhanji JP, Cooney RE, Atlas LY, Gotlib IH (2007) Neural Responses to Monetary Incentives in Major Depression. Biol Psychiatry

Kondo H, Saleem KS, Price JL (2003) Differential connections of the temporal pole with the orbital and medial prefrontal networks in macaque monkeys. J Comp Neurol 465:499-523. doi:10.1002/ cne. 10842

Kondo H, Saleem KS, Price JL (2005) Differential connections of the perirhinal and parahippocampal cortex with the orbital and medial prefrontal networks in macaque monkeys. J Comp Neurol 493:479-509. doi:10.1002/cne.20796

Krishnan KRR, Doraiswamy PM, Lurie SN et al (1991) Pituitary size in depression. J Clin Endocrinol Metab 72:256-259

Krishnan KRR, McDonald WM, Escalona PR et al (1992) Magnetic resonanace imaging of the caudate nuclei in depression: preliminary observations. Arch Gen Psychiatry 49:553-557

Krishnan KRR, McDonald WM, Doraiswamy PM et al (1993) Neuroanatomical substrates of depression in the elderly. Eur Arch Psychiatry Neurosci 243:41-46

Krystal JH, Sanacora G, Blumberg H, Anand A, Charney DS, Marek $\mathrm{G}$ et al (2002) Glutamate and GABA systems as targets for novel antidepressant and mood-stabilizing treatments. Mol Psychiatry 7(suppl 1):S71-S80. doi:10.1038/sj.mp.4001021

Kuroda M, Price JL (1991) Synaptic organization of projections from basal forebrain structures to the mediodorsal thalamic nucleus of the rat. J Comp Neurol 303:513-533. doi:10.1002/cne. 903030402

Lambert G, Johansson M, Agren H, Friberg P (2000) Reduced brain norepinephrine and dopamine release in treatment-refractory depressive illness: evidence in support of the catecholamine hypothesis of mood disorders. Arch Gen Psychiatry 57:787-793. doi:10.1001/archpsyc.57.8.787

Landro NI, Stiles TC, Sletvold H (2001) Neuropsychological function in nonpsychotic unipolar major depression. Neuropsychiatry Neuropsychol Behav Neurol 14:233-240

Ledoux J (2003) The emotional brain, fear, and the amygdala. Cell Mol Neurobiol 23:727-738. doi:10.1023/A:1025048802629

Lesch K (1992) The ipsapirone/5-HT1A receptor challenge in anxiety disorders and depression. In: Stahl S, Hesselink JK, Gastpar M, Traber J (eds) Serotonin 1A receptors in depression and anxiety. New York, Raven Press

Likhtik E, Pelletier JG, Paz R, Pare D (2005) Prefrontal control of the amygdala. J Neurosci 25:7429-7437. doi:10.1523/JNEUROSCI. 2314-05.2005

Lopez JF, Palkovits M, Arato M, Mansour A, Akil H, Watson SJ (1992) Localization and quantification of pro-opiomelanocortin mRNA and glucocorticoid receptor mRNA in pituitaries of suicide victims. Neuroendocrinology 56:491-501. doi:10.1159/ 000126266 
Lopez JF, Chalmers DT, Little KY, Watson SJ (1998) A.E. Bennett Research Award. Regulation of serotonin1A, glucocorticoid, and mineralocorticoid receptor in rat and human hippocampus: implications for the neurobiology of depression. Biol Psychiatry 43:547-573. doi:10.1016/S0006-3223(97)00484-8

Lyoo IK, Kim MJ, Stoll AL, Demopulos CM, Parow AM, Dager SR et al (2004) Frontal lobe gray matter density decreases in bipolar I disorder. Biol Psychiatry 55:648-651. doi:10.1016/j.biopsych. 2003.10.017

MacFall JR, Payne ME, Provenzale JE, Krishnan KR (2001) Medial orbital frontal lesions in late-onset depression. Biol Psychiatry 49:803-806. doi:10.1016/S0006-3223(00)01113-6

Macqueen GM, Galway TM, Hay J, Young LT, Joffe RT (2002) Recollection memory deficits in patients with major depressive disorder predicted by past depressions but not current mood state or treatment status. Psychol Med 32:251-258

Manji HK, Drevets WC, Charney DS (2001) The cellular neurobiology of depression. Nat Med 7:541-547. doi:10.1038/87865

Martinez P, Ronsaville D, Gold PW, Hauser P, Drevets WC (2002) Morphometric abnormalities in adolescent offspring of depressed mothers. Soc Neurosci Abstr 32

Matute C, Sanchez-Gomez MV, Martinez-Millan L, Miledi R (1997) Glutamate receptor-mediated toxicity in optic nerve oligodendrocytes. Proc Natl Acad Sci USA 94:8830-8835. doi:10.1073/ pnas.94.16.8830

Mayberg HS, Brannan SK, Mahurin RK, Jerabek PA, Brickman JS, Tekell JL et al (1997) Cingulate function in depression: a potential predictor of treatment response. NeuroReport 8:10571061. doi:10.1097/00001756-199703030-00048

Mayberg HS, Liotti M, Brannan SK, Mcginnis S, Mahurin RK, Jerabek PA et al (1999) Reciprocal limbic-cortical function and negative mood: converging PET findings in depression and normal sadness. Am J Psychiatry 156:675-682

Mayberg HS, Lozano AM, Voon V, Mcneely HE, Seminowicz D, Hamani $C$ et al (2005) Deep brain stimulation for treatmentresistant depression. Neuron 45:651-660. doi:10.1016/j.neuron. 2005.02.014

McDonald JW, Levine JM, Qu Y (1998) Multiple classes of the oligodendrocyte lineage are highly vulnerable to excitotoxicity. NeuroReport 9:2757-2762. doi:10.1097/00001756-19980824000014

McEwen BS, Magarinos AM (2001) Stress and hippocampal plasticity: implications for the pathophysiology of affective disorders. Hum Psychopharmacol 16:S7-S19. doi:10.1002/hup.266

McGaugh JL (2004) The amygdala modulates the consolidation of memories of emotionally arousing experiences. Annu Rev Neurosci 27:1-28. doi:10.1146/annurev.neuro.27.070203.144157

Mogg K, Bradbury KE, Bradley BP (2006) Interpretation of ambiguous information in clinical depression. Behav Res Ther 44:1411-1419. doi:10.1016/j.brat.2005.10.008

Moore G, Cortese B, Glitz D, Zajac-Benitez C, Quiroz JA, Uhde TW, Drevets WC, Manji HK (2008) Chronic lithium increases prefrontal and subgenual prefrontal gray matter in patients with bipolar disorder: a longitudinal high resolution volumetric MRI study. J Clin Psychiatry

Morgan MA, Ledoux JE (1995) Differential contribution of dorsal and ventral medial prefrontal cortex to the acquisition and extinction of conditioned fear in rats. Behav Neurosci 109:681688. doi:10.1037/0735-7044.109.4.681

Murase S, Grenhoff J, Chouvet G, Gonon FG, Svensson TH (1993) Prefrontal cortex regulates burst firing and transmitter release in rat mesolimbic dopamine neurons studied in vivo. Neurosci Lett 157:53-56. doi:10.1016/0304-3940(93)90641-W

Murphy PC, Sillito AM (1991) Cholinergic enhancement of direction selectivity in the visual cortex of the cat. Neuroscience 40:1320. doi:10.1016/0306-4522(91)90170-S
Murphy FC, Sahakian BJ, Rubinsztein JS, Michael A, Rogers RD, Robbins TW et al (1999) Emotional bias and inhibitory control processes in mania and depression. Psychol Med 29:1307-1321. doi:10.1017/S0033291799001233

Murray LA, Whitehouse WG, Alloy LB (1999) Mood congruence and depressive deficits in memory: a forced-recall analysis. Memory 7:175-196. doi:10.1080/741944068

Musselman D, Nemeroff C (1993) The role of corticotropin-releasing factor in the pathophysiology of psychiatric disorders. Psychiatr Ann 23:676-681

Nahas Z, Teneback C, Chae JH, Mu Q, Molnar C, Kozel FA et al (2007) Serial vagus nerve stimulation functional MRI in treatment-resistant depression. Neuropsychopharmacology 32:1649-1660. doi:10.1038/sj.npp.1301288

Nauta WJH, Domesick V (1984) Afferent and efferent relationships of the basal ganglia. In: Evered D, O'Conner M (eds) Function of the basal ganglia. Pitman Press, London

Nestler EJ, Carlezon WA Jr (2006) The mesolimbic dopamine reward circuit in depression. Biol Psychiatry 59:1151-1159. doi: 10.1016/j.biopsych.2005.09.018

Neumeister A, Nugent AC, Waldeck T, Geraci M, Schwarz M, Bonne $O$ et al (2004) Neural and behavioral responses to tryptophan depletion in unmedicated patients with remitted major depressive disorder and controls. Arch Gen Psychiatry 61:765-773. doi:10.1001/archpsyc.61.8.765

Neumeister A, Drevets WC, Belfer I, Luckenbaugh DA, Henry S, Bonne O et al (2006a) Effects of a alpha 2C-adrenoreceptor gene polymorphism on neural responses to facial expressions in depression. Neuropsychopharmacology 31:1750-1756. doi: 10.1038/sj.npp. 1301010

Neumeister A, Hu XZ, Luckenbaugh DA, Schwarz M, Nugent AC, Bonne $O$ et al (2006b) Differential effects of 5-HTTLPR genotypes on the behavioral and neural responses to tryptophan depletion in patients with major depression and controls. Arch Gen Psychiatry 63:978-986. doi:10.1001/archpsyc.63.9.978

Nobler MS, Sackeim HA, Prohovnik I, Moeller JR, Mukherjee S, Schnur DB et al (1994) Regional cerebral blood flow in mood disorders, III. Treatment and clinical response. Arch Gen Psychiatry 51:884-897

Nugent AC, Milham MP, Bain EE, Mah L, Cannon DM, Marrett S et al (2006) Cortical abnormalities in bipolar disorder investigated with MRI and voxel-based morphometry. Neuroimage 30:485-497. doi:10.1016/j.neuroimage.2005.09.029

Nunn JD, Mathews A, Trower P (1997) Selective processing of concern-related information in depression. Br J Clin Psychol 36(Pt 4):489-503

Nutt DJ (2006) The role of dopamine and norepinephrine in depression and antidepressant treatment. J Clin Psychiatry 67(suppl 6):3-8

Ongür D, Price JL (1998) Prefrontal cortical projections to the hypothalamus in macaque monkeys. J Comp Neurol 401:480 505. doi:10.1002/(SICI)1096-9861(19981130)401:4<480::AID$\mathrm{CNE} 4>3.0 . \mathrm{CO} ; 2-\mathrm{F}$

Ongür D, Price JL (2000) The organization of networks within the orbital and medial prefrontal cortex of rats, monkeys and humans. Cereb Cortex 10:206-219. doi:10.1093/cercor/10.3.206

Ongür D, Drevets WC, Price JL (1998) Glial reduction in the subgenual prefrontal cortex in mood disorders. Proc Natl Acad Sci USA 95:13290-13295. doi:10.1073/pnas.95.22.13290

Ongür D, Ferry AT, Price JL (2003) Architectonic subdivision of the human orbital and medial prefrontal cortex. J Comp Neurol 460:425-449. doi:10.1002/cne.10609

Ottowitz WE, Dougherty DD, Savage CR (2002) The neural network basis for abnormalities of attention and executive function in major depressive disorder: implications for application of the medical disease model to psychiatric disorders. Harv Rev Psychiatry 10:86-99. doi:10.1080/10673220216210 
Overstreet DH (1993) The flinders sensitive line rats: a genetic animal model of depression. Neurosci Biobehav Rev 17:51-68. doi: 10.1016/S0149-7634(05)80230-1

Paul IA, Skolnick P (2003) Glutamate and depression: clinical and preclinical studies. Ann N Y Acad Sci 1003:250-272. doi: 10.1196/annals.1300.016

Perez-Jaranay JM, Vives F (1991) Electrophysiological study of the response of medial prefrontal cortex neurons to stimulation of the basolateral nucleus of the amygdala in the rat. Brain Res 564:97-101. doi:10.1016/0006-8993(91)91357-7

Peterson C, Gibson GE (1983) Amelioration of age-related neurochemical and behavioral deficits by 3,4-diaminopyridine. Neurobiol Aging 4:25-30. doi:10.1016/0197-4580(83)90050-7

Phillips ML, Drevets WC, Rauch SL, Lane R (2003) Neurobiology of emotion perception II: implications for major psychiatric disorders. Biol Psychiatry 54:515-528. doi:10.1016/S0006-3223 (03)00171-9

Pizzagalli D, Pascual-Marqui RD, Nitschke JB, Oakes TR, Larson CL, Abercrombie HC et al (2001) Anterior cingulate activity as a predictor of degree of treatment response in major depression: evidence from brain electrical tomography analysis. Am J Psychiatry 158:405-415. doi:10.1176/appi.ajp.158.3.405

Power AE, Mcgaugh JL (2002) Cholinergic activation of the basolateral amygdala regulates unlearned freezing behavior in rats. Behav Brain Res 134:307-315. doi:10.1016/S0166-4328 (02)00046-3

Price JL (2007) Definition of the orbital cortex in relation to specific connections with limbic and visceral structures and other cortical regions. Ann N Y Acad Sci 1121:54-71. doi:10.1196/annals. 1401.008

Price JL, Carmichael ST, Drevets WC (1996) Networks related to the orbital and medial prefrontal cortex; a substrate for emotional behavior? Prog Brain Res 107:523-536

Purcell R, Maruff P, Kyrios M, Pantelis C (1997) Neuropsychological function in young patients with unipolar major depression. Psychol Med 27:1277-1285. doi:10.1017/S0033291797005448

Radley JJ, Rocher AB, Rodriguez A, Ehlenberger DB, Dammann M, Mcewen BS et al (2008) Repeated stress alters dendritic spine morphology in the rat medial prefrontal cortex. J Comp Neurol 507:1141-1150. doi:10.1002/cne.21588

Rajkowska G, Miguel-Hidalgo JJ, Wei J, Dilley G, Pittman SD, Meltzer HY et al (1999) Morphometric evidence for neuronal and glial prefrontal cell pathology in major depression. Biol Psychiatry 45:1085-1098. doi:10.1016/S0006-3223(99)00041-4

Rajkowska G, Halaris A, Selemon LD (2001) Reductions in neuronal and glial density characterize the dorsolateral prefrontal cortex in bipolar disorder. Biol Psychiatry 49:741-752. doi:10.1016/ S0006-3223(01)01080-0

Rajkowska G, O'Dwyer G, Teleki Z, Stockmeier CA, MiguelHidalgo JJ (2007) GABAergic neurons immunoreactive for calcium binding proteins are reduced in the prefrontal cortex in major depression. Neuropsychopharmacology 32:471-482. doi: 10.1038/sj.npp.1301234

Rauch SL, Jenike MA, Alpert NM, Baer L, Breiter HC, Savage CR et al (1994) Regional cerebral blood flow measured during symptom provocation in obsessive-compulsive disorder using oxygen 15-labeled carbon dioxide and positron emission tomography. Arch Gen Psychiatry 51:62-70

Ravnkilde B, Videbech P, Clemmensen K, Egander A, Rasmussen NA, Rosenberg R (2002) Cognitive deficits in major depression. Scand J Psychol 43:239-251. doi:10.1111/1467-9450.00292

Regenold WT, Phatak P, Marano CM, Gearhart L, Viens CH, Hisley KC (2007) Myelin staining of deep white matter in the dorsolateral prefrontal cortex in schizophrenia, bipolar disorder, and unipolar major depression. Psychiatry Res 151:179-188. doi:10.1016/j.psychres.2006.12.019
Riemann D, Hohagen F, Krieger S, Gann H, Muller WE, Olbrich R et al (1994) Cholinergic REM induction test: muscarinic supersensitivity underlies polysomnographic findings in both depression and schizophrenia. J Psychiatr Res 28:195-210. doi: 10.1016/0022-3956(94)90006-X

Rolls ET (1995) A theory of emotion and consciousness, and its application to understanding the neural basis of emotion. In: Gazzaniga MS (ed) The cognitive neurosciences. MIT Press, Cambridge

Rose EJ, Ebmeier KP (2006) Pattern of impaired working memory during major depression. J Affect Disord 90:149-161. doi: 10.1016/j.jad.2005.11.003

Rosoklija G, Toomayan G, Ellis SP, Keilp J, Mann JJ, Latov N et al (2000) Structural abnormalities of subicular dendrites in subjects with schizophrenia and mood disorders: preliminary findings. Arch Gen Psychiatry 57:349-356. doi:10.1001/archpsyc. 57.4.349

Rubin RT, O’Toole SM, Rhodes ME, Sekula LK, Czambel RK (1999) Hypothalamo-pituitary-adrenal cortical responses to low-dose physostigmine and arginine vasopressin administration: sex differences between major depressives and matched control subjects. Psychiatry Res 89:1-20. doi:10.1016/S0165-1781 (99)00085-2

Russchen FT, Bakst I, Amaral DG, Price JL (1985) The amygdalostriatal projections in the monkey. An anterograde tracing study. Brain Res 329:241-257. doi:10.1016/0006-8993(85)90530-X

Rusted JM, Warburton DM (1988) The effects of scopolamine on working memory in healthy young volunteers. Psychopharmacology (Berl) 96:145-152

Saleem KS, Kondo H, Price JL (2008) Complementary circuits connecting the orbital and medial prefrontal networks with the temporal, insular, and opercular cortex in the macaque monkey. J Comp Neurol 506:659-693. doi:10.1002/cne.21577

Saleem KS, Price JL, Hashikawa T (2007) Cytoarchitectonic and chemoarchitectonic subdivisions of the perirhinal and parahippocampal cortices in macaque monkeys. J Comp Neurol 500:973-1006. doi:10.1002/cne.21141

Sanacora G, Mason GF, Rothman DL, Behar KL, Hyder F, Petroff OA et al (1999) Reduced cortical gamma-aminobutyric acid levels in depressed patients determined by proton magnetic resonance spectroscopy. Arch Gen Psychiatry 56:1043-1047. doi:10.1001/archpsyc.56.11.1043

Santamaria J, Tolosa E, Valles A (1986) Parkinson's disease with depression: a possible subgroup of idiopathic parkinsonism. Neurology 36:1130-1133

Santarelli L, Saxe M, Gross C, Surget A, Battaglia F, Dulawa S et al (2003) Requirement of hippocampal neurogenesis for the behavioral effects of antidepressants. Science 301:805-809. doi: $10.1126 /$ science. 1083328

Sargent PA, Kjaer KH, Bench CJ, Rabiner EA, Messa C, Meyer J et al (2000) Brain serotonin1A receptor binding measured by positron emission tomography with [11C]WAY-100635: effects of depression and antidepressant treatment. Arch Gen Psychiatry 57:174-180. doi:10.1001/archpsyc.57.2.174

Sarter M, Nelson CL, Bruno JP (2005) Cortical cholinergic transmission and cortical information processing in schizophrenia. Schizophr Bull 31:117-138. doi:10.1093/schbul/sbi006

Sato H, Hata Y, Masui H, Tsumoto T (1987) A functional role of cholinergic innervation to neurons in the cat visual cortex. J Neurophysiol 58:765-780

Schlaepfer TE, Cohen MX, Frick C, Kosel M, Brodesser D, Axmacher N, Joe AY, Kreft M, Lenartz D, Sturm V (2008) Deep brain stimulation to reward circuitry alleviates anhedonia in refractory major depression. Neuropsychopharmacology 33:368-377

Schneider F, Gur RE, Mozley LH, Smith RJ, Mozley PD, Censits DM et al (1995) Mood effects on limbic blood flow correlate with 
emotional self-rating: a PET study with oxygen-15 labeled water. Psychiatry Res 61:265-283. doi:10.1016/0925-4927(95) 02678-Q

Schultz W, Dayan P, Montague PR (1997) A neural substrate of prediction and reward. Science 275:1593-1599. doi: 10.1126/science.275.5306.1593

Shekhar A, Truitt W, Rainnie D, Sajdyk T (2005) Role of stress, corticotrophin releasing factor (CRF) and amygdala plasticity in chronic anxiety. Stress 8:209-219. doi:10.1080/102538905 00504557

Sheline YI, Barch DM, Donnelly JM, Ollinger JM, Snyder AZ, Mintun MA (2001) Increased amygdala response to masked emotional faces in depressed subjects resolves with antidepressant treatment: an fMRI study. Biol Psychiatry 50:651-658. doi: 10.1016/S0006-3223(01)01263-X

Sheline YI, Gado MH, Kraemer HC (2003) Untreated depression and hippocampal volume loss. Am J Psychiatry 160:1516-1518. doi: 10.1176/appi.ajp.160.8.1516

Shulman RG, Rothman DL, Behar KL, Hyder F (2004) Energetic basis of brain activity: implications for neuroimaging. Trends Neurosci 27:489-495. doi:10.1016/j.tins.2004.06.005

Siegle GJ, Steinhauer SR, Thase ME, Stenger VA, Carter CS (2002) Can't shake that feeling: event-related fMRI assessment of sustained amygdala activity in response to emotional information in depressed individuals. Biol Psychiatry 51:693-707. doi: 10.1016/S0006-3223(02)01314-8

Siegle GJ, Carter CS, Thase ME (2006) Use of FMRI to predict recovery from unipolar depression with cognitive behavior therapy. Am J Psychiatry 163:735-738. doi:10.1176/appi.ajp.163.4.735

Sillito AM, Kemp JA (1983) Cholinergic modulation of the functional organization of the cat visual cortex. Brain Res 289:143-155. doi:10.1016/0006-8993(83)90015-X

Sitaram N, Weingartner H, Gillin JC (1978) Human serial learning: enhancement with arecholine and choline impairment with scopolamine. Science 201:274-276. doi:10.1126/science.351808

Starkstein SE, Robinson RG (1989) Affective disorders and cerebral vascular disease. Br J Psychiatry 154:170-182

Stockmeier CA (2003) Involvement of serotonin in depression: evidence from postmortem and imaging studies of serotonin receptors and the serotonin transporter. J Psychiatr Res 37:357373. doi:10.1016/S0022-3956(03)00050-5

Stockmeier CA, Mahajan GJ, Konick LC, Overholser JC, Jurjus GJ, Meltzer HY et al (2004) Cellular changes in the postmortem hippocampus in major depression. Biol Psychiatry 56:640-650. doi:10.1016/j.biopsych.2004.08.022

Stordal KI, Lundervold AJ, Egeland J, Mykletun A, Asbjornsen A, Landro NI et al (2004) Impairment across executive functions in recurrent major depression. Nord J Psychiatry 58:41-47. doi: 10.1080/08039480310000789

Sullivan RM, Gratton A (1999) Lateralized effects of medial prefrontal cortex lesions on neuroendocrine and autonomic stress responses in rats. J Neurosci 19:2834-2840

Sullivan PF, Neale MC, Kendler KS (2000) Genetic epidemiology of major depression: review and meta-analysis. Am J Psychiatry 157:1552-1562. doi:10.1176/appi.ajp.157.10.1552

Surguladze S, Brammer MJ, Keedwell P, Giampietro V, Young AW, Travis MJ et al (2005) A differential pattern of neural response toward sad versus happy facial expressions in major depressive disorder. Biol Psychiatry 57:201-209. doi:10.1016/j.biopsych. 2004.10.028

Swaab DF, Bao AM, Lucassen PJ (2005) The stress system in the human brain in depression and neurodegeneration. Ageing Res Rev 4:141-194. doi:10.1016/j.arr.2005.03.003

Swerdlow NR, Koob GF (1987) Dopamine, schizophrenia, mania, and depression: toward a unified hypothesis of cortico-striatothalamic function. Behav Brain Sci 10:197-245
Taber MT, Fibiger HC (1993) Electrical stimulation of the medial prefrontal cortex increases dopamine release in the striatum. Neuropsychopharmacology 9:271-275

Tavares JV, Drevets WC, Sahakian BJ (2003) Cognition in mania and depression. Psychol Med 33:959-967. doi:10.1017/ S0033291703008432

Taylor Tavares JV, Clark L, Cannon DM, Erickson K, Drevets WC, Sahakian BJ (2007) Distinct profiles of neurocognitive function in unmedicated unipolar depression and bipolar II depression. Biol Psychiatry 62:917-924. doi:10.1016/j.biopsych.2007. 05.034

Tham A, Engelbrektson K, Mathe AA, Johnson L, Olsson E, AbergWistedt A (1997) Impaired neuropsychological performance in euthymic patients with recurring mood disorders. J Clin Psychiatry 58:26-29

Thomas KM, Drevets WC, Dahl RE, Ryan ND, Birmaher B, Eccard $\mathrm{CH}$ et al (2001) Amygdala response to fearful faces in anxious and depressed children. Arch Gen Psychiatry 58:1057-1063. doi: 10.1001/archpsyc.58.11.1057

Timms RJ (1977) Cortical inhibition and facilitation of the defence reaction. J Physiol (Proceedings) 266:98P-99P

Todtenkopf MS, Vincent SL, Benes FM (2005) A cross-study metaanalysis and three-dimensional comparison of cell counting in the anterior cingulate cortex of schizophrenic and bipolar brain. Schizophr Res 73:79-89. doi:10.1016/j.schres.2004.08.018

Tsourtos G, Thompson JC, Stough C (2002) Evidence of an early information processing speed deficit in unipolar major depression. Psychol Med 32:259-265

Uranova N, Orlovskaya D, Vikhreva O, Zimina I, Kolomeets N, Vostrikov V et al (2001) Electron microscopy of oligodendroglia in severe mental illness. Brain Res Bull 55:597-610. doi: 10.1016/S0361-9230(01)00528-7

Uranova NA, Vostrikov VM, Orlovskaya DD, Rachmanova VI (2004) Oligodendroglial density in the prefrontal cortex in schizophrenia and mood disorders: a study from the Stanley Neuropathology Consortium. Schizophr Res 67:269-275. doi: 10.1016/S0920-9964(03)00181-6

Van Laere K, Nuttin B, Gabriels L, Dupont P, Rasmussen S, Greenberg BD et al (2006) Metabolic imaging of anterior capsular stimulation in refractory obsessive-compulsive disorder: a key role for the subgenual anterior cingulate and ventral striatum. J Nucl Med 47:740-747

Veith RC, Lewis N, Linares OA, Barnes RF, Raskind MA, Villacres EC et al (1994) Sympathetic nervous system activity in major depression. Basal and desipramine-induced alterations in plasma norepinephrine kinetics. Arch Gen Psychiatry 51:411-422

Vidal-Gonzalez I, Vidal-Gonzalez B, Rauch SL, Quirk GJ (2006) Microstimulation reveals opposing influences of prelimbic and infralimbic cortex on the expression of conditioned fear. Learn Mem 13:728-733. doi:10.1101/lm.306106

Vostrikov VM, Uranova NA, Orlovskaya DD (2007) Deficit of perineuronal oligodendrocytes in the prefrontal cortex in schizophrenia and mood disorders. Schizophr Res 94:273-280. doi:10.1016/j.schres.2007.04.014

Vyas A, Mitra R, Shankaranarayana Rao BS, Chattarji S (2002) Chronic stress induces contrasting patterns of dendritic remodeling in hippocampal and amygdaloid neurons. J Neurosci 22:6810-6818

Vyas A, Bernal S, Chattarji S (2003) Effects of chronic stress on dendritic arborization in the central and extended amygdala. Brain Res 965:290-294. doi:10.1016/S0006-8993(02)04162-8

Vyas A, Jadhav S, Chattarji S (2006) Prolonged behavioral stress enhances synaptic connectivity in the basolateral amygdala. Neuroscience 143:387-393. doi:10.1016/j.neuroscience.2006.08.003

Vythilingam M, Heim C, Newport J, Miller AH, Anderson E, Bronen $\mathrm{R}$ et al (2002) Childhood trauma associated with smaller 
hippocampal volume in women with major depression. Am J Psychiatry 159:2072-2080. doi:10.1176/appi.ajp.159.12.2072

Wang JC, Hinrichs AL, Stock H, Budde J, Allen R, Bertelsen S et al (2004) Evidence of common and specific genetic effects: association of the muscarinic acetylcholine receptor M2 (CHRM2) gene with alcohol dependence and major depressive syndrome. Hum Mol Genet 13:1903-1911. doi:10.1093/hmg/ ddh 194

Webster MJ, Knable MB, Johnston-Wilson N, Nagata K, Inagaki M, Yolken RH (2001) Immunohistochemical localization of phosphorylated glial fibrillary acidic protein in the prefrontal cortex and hippocampus from patients with schizophrenia, bipolar disorder, and depression. Brain Behav Immun 15:388-400. doi: 10.1006/brbi.2001.0646
Wellman CL (2001) Dendritic reorganization in pyramidal neurons in medial prefrontal cortex after chronic corticosterone administration. J Neurobiol 49:245-253. doi:10.1002/neu.1079

WHO (2001) The world health report. http://www.who.int; Chap 2,4 Willner P (1995) Dopaminergic mechanisms in depression and mania. In: Bloom FE, Kupfer DJ (eds) Psychopharmacology: the fourth generation of progress. Raven Press, New York

Young EA, Kotun J, Haskett RF, Grunhaus L, Greden JF, Watson SJ et al (1993) Dissociation between pituitary and adrenal suppression to dexamethasone in depression. Arch Gen Psychiatry 50:395-403

Zarate CA Jr, Payne JL, Singh J, Quiroz JA, Luckenbaugh DA, Denicoff KD et al (2004) Pramipexole for bipolar II depression: a placebo-controlled proof of concept study. Biol Psychiatry 56:54-60. doi:10.1016/j.biopsych.2004.03.013 